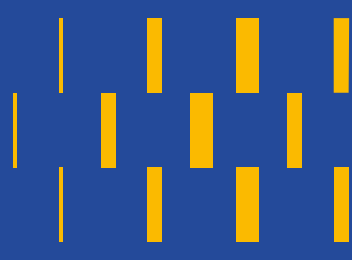

\title{
Animales en acción: usos rituales de fauna silvestre y de representaciones zoomorfas en contextos incaicos del Pucará de Tilcara (Quebrada de Humahuaca, Argentina)
}

\section{Animals in action: ritual uses of wildlife and zoomorphic representations in inca contexts of Pucará de Tilcara (Quebrada de Humahuaca, Argentina)}

\author{
Clarisa Otero ${ }^{1,2}$ (D) https://orcid.org/0000-0001-6408-2955 \\ Mauricio Sebastián Akmentins ${ }^{3}$ (D) https://orcid.org/0000-0003-1313-9899 \\ Andrés Sebastián Quinteros ${ }^{4,5}$ (D) https://orcid.org/0000-0002-0363-9163
${ }^{1}$ Instituto de Datación y Arqueometría, CONICET, UNJu, UNT, Gob. de Jujuy, Jujuy, ARGENTINA. Email: clarisaotero@yahoo.com.ar
${ }^{2}$ Instituto Interdisciplinario Tilcara, FFyL, Universidad de Buenos Aires, Buenos Aires, ARGENTINA.
${ }^{3}$ Instituto de Ecorregiones Andinas (INECOA), CONICET, UNJu, Jujuy, ARGENTINA.
Email: msakmentins@conicet.gov.ar
${ }^{4}$ Instituto de Bio y Geociencias del NOA, CONICET-UNSa (Universidad Nacional de Salta),
ARGENTINA. Email: sebasquint@gmail.com
${ }^{5}$ Cátedra de Sistemática Filogenética, Facultad de Ciencias Naturales, Universidad Nacional de Salta, Salta, ARGENTINA.

\section{Resumen}

Las prácticas político-religiosas incaicas se consolidaron con la articulación de creencias y rituales que contemplaban divinidades tanto del medio natural como sobrenatural. Durante su divulgación a lo largo del Tawantinsuyu se fortalecieron a partir de la evocación de un pasado mítico que condicionaba el presente y de la veneración de una amplia gama de animales, seres humanos o de naturaleza mixta, entidades del orden estelar y elementos del paisaje. En este trabajo analizamos las evidencias que refieren a las manifestaciones religiosas de los pobladores del Pucará de Tilcara, definido como capital de la provincia incaica de Omaguaca. Entre el conjunto de materialidades, mediante un enfoque interdisciplinario nutrido principalmente por la herpetología, estudiamos los contextos arqueológicos que involucraron la manipulación de fauna silvestre, así como el uso de objetos con variadas representaciones zoomorfas. La interpretación del registro arqueológico, apelando también a su correlación con fuentes antropológicas y etnohistóricas, permite sostener que ciertos animales, así como sus representaciones, funcionaron como medios activos del entorno natural para propiciar la fertilidad, promover la reproducción socioeconómica de las comunidades, acceder al poder germinativo de los ancestros e identificar marcas climáticas y temporales.

Palabras clave: religión andina, animales sagrados, fertilidad, estudio interdisciplinario, materialidades. 


\begin{abstract}
Inca religious beliefs and practices, with greater emphasis during its promulgation throughout the Tawantinsuyu, were consolidated with the articulation of ideas and rituals from the natural and supernatural environment. They get improved with the evocation of a mythical past that conditioned the present, and the veneration of a wide range of beings and elements of the stellar, human, animal and landscape order. In this work we analyze the evidence that refers to the religious manifestations of the inhabitants of Pucará de Tilcara, defined as the capital of the Inca province of Omaguaca. Among the set of materialities, through an interdisciplinary approach nourished mainly by herpetology, we study the archaeological contexts that involved the manipulation of wildlife, as well as the use of objects with varied zoomorphic representations. The interpretation of the archaeological record, also appealing to its correlation with anthropological and ethnohistoric sources, allowed us to say that certain animals, as well as their representations, functioned as active means of the natural environment to encourage fertility, promote the socioeconomic reproduction of communities, access to the germination power of ancestors and identify climatic and temporal marks.
\end{abstract}

Keywords: Andean religion, sacred animals, fertility, interdisciplinary approach, materialities.

Recibido: 31 diciembre 2019. Aceptado: 16 septiembre 2020 


\section{Introducción}

La religión de las sociedades andinas prehispánicas ha sido materia de estudio desde la llegada de los europeos. Debido a que la legitimidad de las autoridades y la constitución de las identidades tenían una fuerte base cosmológica (Rostworowski, 1999; Rowe, 2003; Ramírez, 2008; Zuidema, 2015), fue necesario comprender aquellos aspectos que consolidaban el poder para lograr su rápida desestructuración. En el caso particular de la religión incaica, con las descripciones de los primeros cronistas se da cuenta de manera temprana de una extrema complejidad en el sistema de creencias que aún hoy, y a pesar del abundante número de obras etnohistóricas, antropológicas y arqueológicas sobre el tema, es difícil ordenar de modo jerárquico para determinar niveles de prevalencia de determinados cultos, deidades o prácticas. Se trata de un sistema en el que todo esquema parte de una interrelación de ideas asociadas tanto al mundo natural como sobrenatural, con anclajes que evocan un pasado mítico que continúa condicionando el presente, y de veneraciones a una amplia gama de seres y elementos del orden estelar, humano, animal y del paisaje (Kosiba y Bauer, 2014; Kosiba, 2016).

El conjunto de estas veneraciones involucró una variada parafernalia puesta en escena con particularidades propias de cada territorio anexado al Tawantinsuyu (Bauer, 2000; Malpass y Alconini, 2010; Bray, 2015; Shimada, 2018). En cada provincia la promoción de las bases religiosas adquirió matices distintivos según la relevancia de las wak’as regionales, la abundancia de los recursos naturales presentados en las ceremonias y el estatus de los ancestros dentro del sistema general de linajes incaicos. No obstante, independientemente del lugar de ejecución y quizás por ser un rasgo común, de carácter panandino, en toda práctica ritual fue habitual la manipulación de restos humanos y de animales junto al consumo de bebidas y alimentos, y el uso simbólico de imágenes en distintos soportes para expresar manifestaciones ligadas al culto al sol, los ancestros y la fertilidad (Polo de Ondergardo, 1571; Murúa, 1573; Albornoz, 1580; Bertonio, 1603a y b; Guaman Poma de Ayala, 1615; Ramos Gavilán, 1621; Cobo, 1653). A lo largo del desarrollo del Estado Incaico, estos cultos funcionaron en concordancia para lograr la reproducción social e integración de una amplia pluralidad religiosa y étnica. Con Pachacuti Inca Yupanqui, legítimo descendiente del Sol, el culto solar se instauró como la principal creencia para impregnar de su soberanía a todos los dominios y lograr una imperante estabilidad en las comunidades (Ramírez, 2008). Además de unificar manifestaciones con la intención de crear una única memoria colectiva, la veneración al sol también fue rectora del ritmo de las actividades económicas. Las fechas en las que se la profesaba con más ímpetu guardaban correspondencia con el inicio y fin de los ciclos productivos (Zuidema, 1977).

En el calendario ritual, más allá de servir de guía, como los movimientos del sol y otras entidades celestes, el comportamiento de determinados animales también funcionó como indicador temporal, particularmente el de aquellos vinculados a los ciclos estacionales y el agua. A partir del estudio de numerosos contextos y objetos detectados en el Pucará de Tilcara, considerado la cabecera política de la wamani de Omaguaca, reconocemos estas manifestaciones, llegando a entender que al igual que para el caso de otras provincias distantes del centro del Imperio, en la quebrada de Humahuaca (provincia de Jujuy, Argentina), debió producirse una notoria resemantización de las ceremonias incaicas. En el Pucará resulta llamativa la aparición de restos esqueletales de animales en diferentes contextos, que podría manifestar su manipulación e inclusión en eventos rituales. En áreas de uso ceremonial también se recuperaron objetos que, por sus atributos y representaciones de especies vinculadas a las variaciones climáticas y fuentes de agua, permiten reconocer prácticas que pudieron propiciar la fertilidad. En este trabajo 
avanzamos en la definición de estos hallazgos a partir del análisis contextual de las distintas representaciones con una mirada interdisciplinaria, generada de la articulación entre la arqueología y la biología, específicamente la herpetología, la revisión de la documentación histórica y el análisis de las evidencias arqueológicas en correlato con la información antropológica. El análisis de los materiales no solo involucró los objetos y muestras faunísticas recuperados en nuestras tareas de excavación, sino también contempló la revisión de las colecciones del Pucará de Tilcara conservadas en los museos Arqueológico "Eduardo Casanova” y Etnográfico "Juan Bautista Ambrosetti", ambos de la Facultad de Filosofía y Letras de la Universidad de Buenos Aires, en el Museo Argentino de Ciencias Naturales "Bernardino Rivadavia" y en el Museo de Ciencias Naturales de la Universidad Nacional de La Plata.

\section{Grabados, dibujos y modelados de animales emblemáticos}

Durante la dominación incaica de la quebrada de Humahuaca, el Pucará de Tilcara cumplió con múltiples funciones. En trabajos previos destacamos su rol jerárquico como centro político y productivo de una de las cinco principales provincias incaicas definidas para el noroeste argentino (Otero, Cremonte y Ochoa, 2018). En este caso, el tipo de evidencias analizadas lleva a evaluar su carácter religioso a escala regional, en el que se integró quizás como escenario de numerosas ceremonias que debieron ejecutarse de manera encadenada a otras desarrolladas en las wak'as circundantes (Ochoa y Otero, 2020). Entre las casi 600 estructuras que conforman el Pucará, un edificio que permite caracterizar parte de estas celebraciones es el tradicionalmente conocido como "La Iglesia" (Debenedetti, 1930, p. 38-45), emplazado 25 m por debajo de la altura de la cúspide del sitio (Figura 1). Este conjunto arquitectónico, que podría ser descripto como un rectángulo perimetral compuesto (sensu Madrazo y Otonello, 1966, p. 12) o kancha (sensu Hyslop, 1990, p. 16), fue reconstruido en dos etapas. La primera durante los trabajos de Debenedetti en la década de 1920 y la segunda durante las tareas dirigidas por Casanova en la década de 1970. Cuenta con recintos de diversos tamańos y formas adosados a grandes patios.

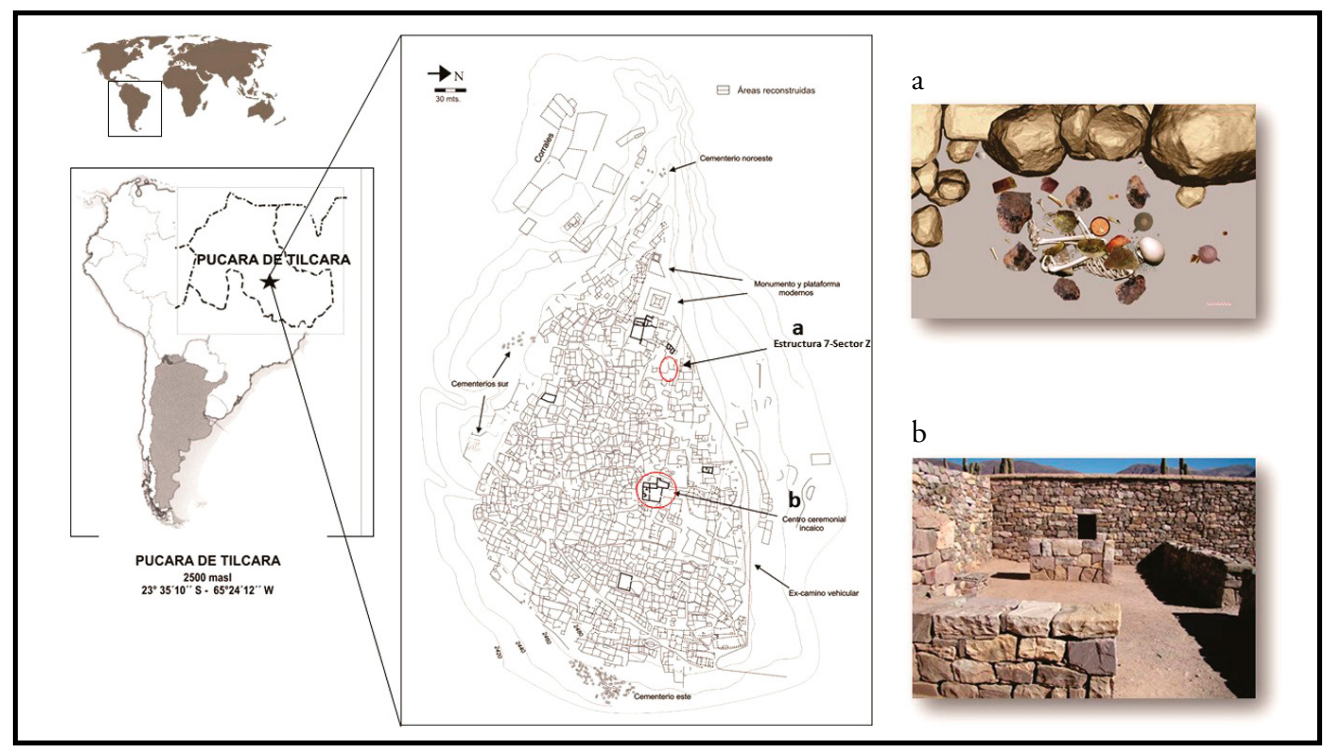

Figura 1. Plano del Pucará de Tilcara (Modificados de Zaburlín y Otero 2014):

a) contexto mortuorio identificado en la Estructura 7 del Sector Z (figura en 3D realizada por Jorge González), b) vista del centro ceremonial incaico actualmente reconstruido. 
Esta disposición debió estar sujeta a su principal función, que involucraba la observación de los movimientos del sol y de otros fenómenos astronómicos (Otero y Ochoa, 2011).

En el recinto principal de este conjunto se detectaron dos mesas construidas en piedra, que alrededor presentaban objetos de distinta procedencia, dos esqueletos de adultos enterrados en una esquina y un cráneo, también de una persona adulta, junto a una estructura rectangular construida con rocas, que en su interior contenía dos platos ornitomorfos. La presencia de estos restos óseos humanos podría reflejar ceremonias ligadas al culto a los ancestros. No obstante, con la intención de lograr la reconstrucción de las prácticas que allí se desarrollaron, no solo las referidas al culto al sol y los antepasados, se revisó el conjunto de objetos presentes en los museos de la FFyL-UBA y Museo Argentino de Ciencias Naturales "Bernardino Rivadavia”, y se reinterpretó la información presentada por Debenedetti en sus diarios de campo $(1928 / 1929,1930)$ (Otero, 2015). Entre el conjunto cerámico, compuesto en su mayoría por piezas de fina calidad de origen no local, tales como aríbalos, jarras, ollas con pie y platos ornitormorfos, se distingue una vasija anuromorfa. El modelado y coloreado de anfibios en cerámica resulta una práctica común que trasciende al mundo andino, quizás buscando representar distintos atributos de diferentes especies, incluso su toxicidad (Pérez, Schuster y Jofré, 2018). En el caso del ejemplar hallado en la kancha, en su momento por el tipo de moteado lo adscribimos al estilo Inca Pacajes. Sin embargo, los atributos modelados y pintados en esta pieza, más que responder a los motivos decorativos característicos de este estilo cerámico, llevan a suponer que guardan relación con los rasgos de las ranas acuáticas del género Telmatobius que habitan en toda la extensión del Tawantinsuyu (ver mapa en Barrionuevo, 2017). Llama la atención el nivel de detalle que presenta esta pieza, que la diferencia claramente del resto de las representaciones animales de los objetos ceremoniales hallados en la kancha (Figura 2). En la figura se destacan la orientación de los ojos hacia adelante, una característica propia de las ranas del género Telmatobius que la diferencia del resto de los anfibios de la región, y el fino patrón de manchas oscuras que le dan un aspecto marmolado al anfibio representado (Akmentins y

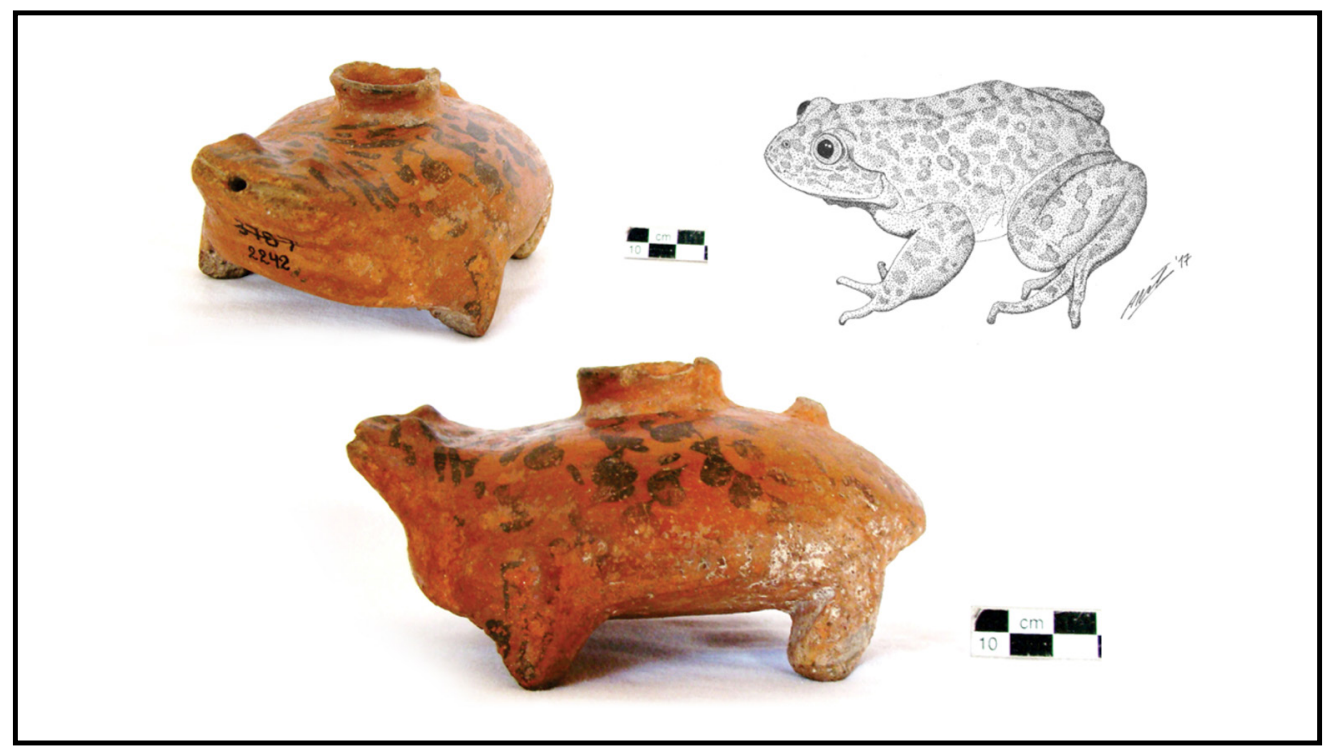

Figura 2. Vasija anuromorfa MT (Museo Arqueológico Tilcara) 2242-MEJBA

(Museo Etnográfico Juan B. Ambrosetti) 3707. Ilustración de un ejemplar de Telmatobius marmoratus. Ilustración de M.S. Akmentins, 2017. 
Otero, 2016; Otero, Akmentins e Ibarra, 2018b). En la quebrada existen dos especies de este género. En el río Huasamayo que alimenta de agua a la localidad de Tilcara habita la especie Telmatobius oxycephalus, en tanto que en la cuenca superior del Río Grande y en las regiones puneñas del noroeste de Argentina y Bolivia se encuentra la especie Telmatobius marmoratus (Lavilla y Barrionuevo, 2005; Frost, 2020). La Rana Gigante del Titicaca (Telmatobius culeus), continúa siendo uno de los principales protagonistas en los ritos propiciatorios (Elías, Ramos, García, Herbert y Quispe, 2019). Al extraerlas del medio acuático y dejarlas secar, en ocasiones dentro de vasijas, aún hoy las comunidades lacustres las utilizan para invocar las lluvias. Su uso, como llamadores de agua, tiene una larga profundidad histórica. De la misma forma, la rana modelada en cerámica, hallada en el edificio ceremonial del Pucará, pudo ser utilizada para propiciar las precipitaciones y, por lo tanto, la fertilidad. Esta pieza, que cuenta con un orificio vertedor en la boca y un asa, actualmente ausente pero que pudo permitir asirla fácilmente por el lomo, debió utilizarse para libar la tierra.

En la kancha, otros elementos también remiten a este sentido propiciatorio. Próxima a la vasija anuromorfa se encontró una valva de molusco del género Pecten (Figura 3a). Según Bauer (2000), las conchas marinas eran parte de los objetos más frecuentemente ofrecidos en los ritos de agua. Murra (2002, p. 172) menciona que entre las ofrendas entregadas a las wak'as se incluía mullu para pedir por lluvias. En la quebrada de Humahuaca se encontraron pocos ejemplares de Spondylus princeps (p.e., La Huerta). Por la larga distancia a su zona de origen, quizás en la quebrada se lo sustituyó por el Pecten, atendiendo a su color similar al mullu de tonos morados. En el Pucará esta especie aparece de manera abundante junto a otras igualmente procedentes de la costa pacífica, tales como Turritella cingulata, Concholepas concholepas, Semele corrugata, Mytilus sp., entre otras (Figura 3b, c y d). A partir de la revisión de las colecciones en los museos previamente mencionados, y de nuestras tareas de excavación, se pudo determinar que más allá del uso ritual, muchas valvas fueron aprovechadas en los talleres artesanales para confeccionar objetos suntuarios (Otero y Tarragó, 2017) (Figura 3e).
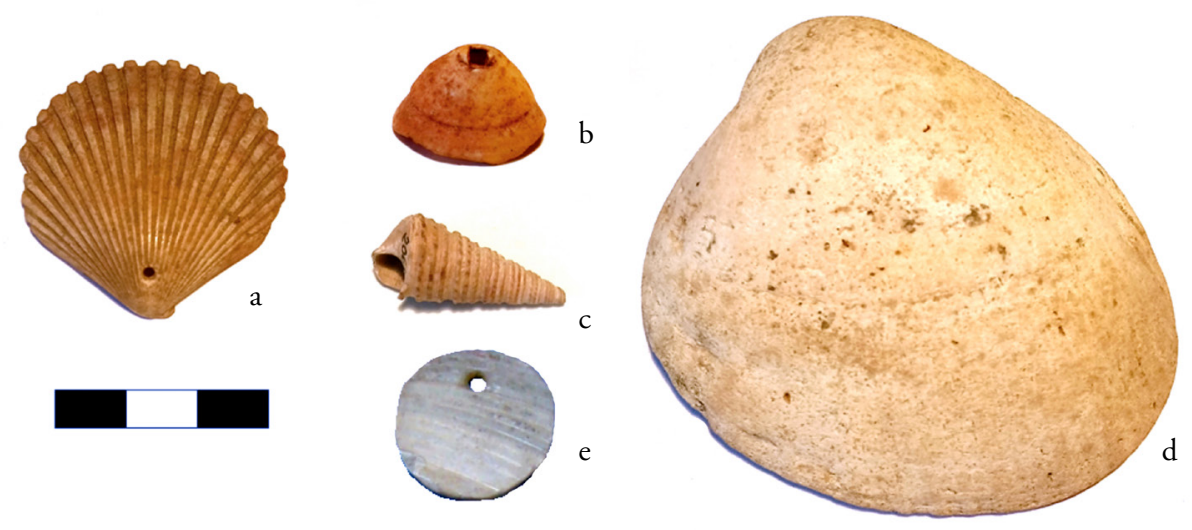

Figura 3. Fotografías de ejemplares y valvas de moluscos encontrados en el Pucará de Tilcara: a) valva del género Pecten (Museo Argentino de Ciencias Naturales MACN BR 20772, MEJBA 3706),

b) valva de Scurria scurra (MACN BR 20757-MEJBA 3768), c) Turritella cingulata (MACN BR 20719),

d) Concholepas concholepas (MCAN BR 20704- MEJBA 3740), e) pequeño disco de nácar (MEJBA 28332). 
Otro objeto detectado en esta kancha, una illa zoomorfa confeccionada en roca, también pudo formar parte de las ofrendas destinadas a favorecer la fertilidad, a través de la multiplicación de los camélidos. En los talleres lapidarios del Pucará es frecuente detectar restos de producción de la manufactura de tallas en ónix, caliza, travertino y alabastro. La elaboración especializada de estos objetos posiblemente demuestre un uso simbólico a escala regional. Hasta el presente, se cree que las illas, mediante su incorporación, tienen el poder de adquirir las propiedades del objeto al que simbólicamente reemplazan. Este tipo de reemplazo es otra de las tantas creencias de profunda raigambre andina que considera que a través de la representación figurada se produce un interjuego de entidades, en el que se manipulan distintas dimensiones (Cornejo, 1998). Así, estas pequeñas tallas llegan a contener la potencia de los seres vivos que representan de forma prolongada, lo que explica la causa por la que se traspasan por generaciones (Manríquez, 1999). La sucesión de estos símbolos incluso permite obtener las facultades de los ancestros para interceder ante determinados eventos climáticos. Este puede ser el caso de un colgante también hallado en este centro ceremonial, que podría simular la representación de un quirquincho. El brillo y el desgaste que presenta pueden reflejar su uso reiterado en el tiempo. Lo mismo sucede con otras illas que simbolizan camélidos, marlos de maíz, un felino y un caracol marino del género Turritella (Figura 4). Estas últimas fueron encontradas en el sector de la cima del Pucará donde estimamos que se hallaba un ushnu, según las descripciones de Ambrosetti, quien denomina a este sector como Acrópolis, y donde reconocimos objetos de alto valor religioso (Zaburlín y Otero, 2014).
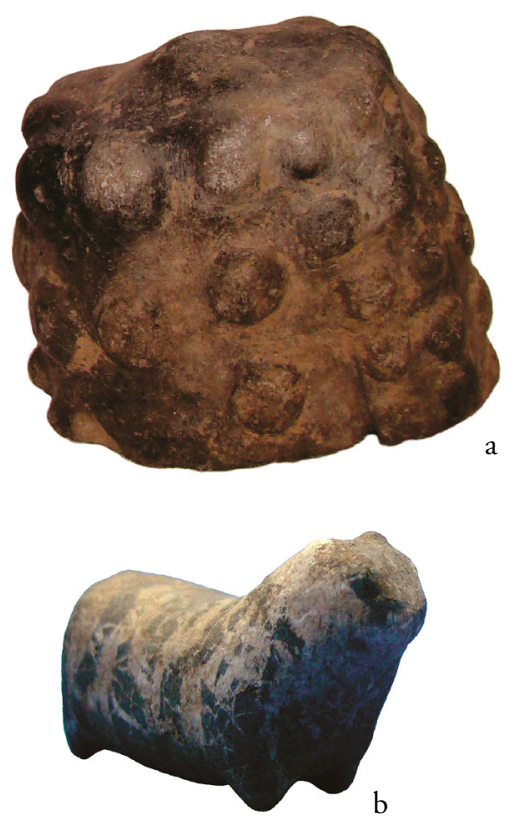
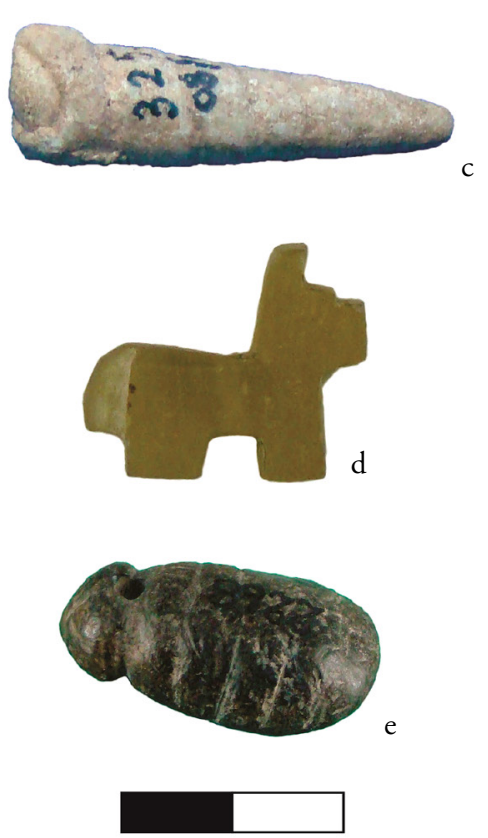

Figura 4. Illas confeccionadas en roca, halladas en el Pucará de Tilcara: a) representación de una mazorca

(MT 2580), b) representación de una figura zoomorfa, quizás un felino (MEJBA 8204),

c) representación de un caracol marino (MEJBA 3254), d) representación de un camélido elaborado en ónix (Museo de Ciencias Naturales de La Plata: MLP-AR-N 7365), e) representación de un posible armadillo confeccionado en lutita (MT 2268). 
Los objetos recuperados en la kancha remiten al desarrollo de prácticas que debieron tener como fin último regular los ciclos productivos con los ciclos estacionales. En este espacio principalmente se debieron promulgar celebraciones propiciatorias de la fertilidad, necesariamente articuladas con otros ritos destinados al culto a los ancestros y al sol, quienes en definitiva eran los legítimos responsables de la regeneración de los cultivos y animales, las vetas de minerales y las lluvias. Era menester de los antepasados incidir favorablemente en las características del ambiente para así evitar desastres naturales, tales como sequías, caída de granizos y aludes. Esto motivaba la veneración continua de sus figuras, colocando un importante número de ofrendas para minimizar represalias como la aparición de inclemencias climáticas. Si bien la quebrada de Humahuaca, durante la dominación incaica, presentaba ventajas insuperables, en relación a otras regiones de los Andes centro-sur, dada su proximidad a los bolsones fértiles de las Yungas y la posibilidad de cultivar grandes extensiones agrícolas, en esta región el agua siempre fue un recurso escaso como para sustentar una vasta población abocada a diferentes labores y como para ser utilizada abundantemente durante la producción metalúrgica y lapidaria. En esta última actividad, el agua era necesaria para el corte y pulido de las tallas (Krapovickas, 1958/1959). Por tal razón es de suponer que la invocación de las lluvias y el pedido de regeneración de las vertientes involucrara numerosos actos performativos en distintos lugares del paisaje, en los que se debieron desplegar todo tipo de objetos evocativos. La presencia de un gran número de platos ornitomorfos en los sectores más elevados del Pucará, no solo en la kancha, también puede ser entendida como una manifestación de estas creencias, ya que en su mayoría representan aves características de diversos medios acuáticos altoandinos. Por otro lado, estos platos o chuwas, tal como se observa en las crónicas, eran considerados objetos de idolatría (Arriaga, 1621), mientras que en contextos actuales siguen en vigencia y ligados al ceremonialismo, por utilizarse como contenedores de elementos de importante valor ritual (Núñez y Castro, 2011).

Del mismo modo, otros objetos representan explícita o implícitamente seres ligados a los ciclos estacionales de la lluvia. Por una parte, en el Pucará se detectaron discos de metal e instrumentos de hueso con grabados de serpientes y un amplio conjunto de piezas cerámicas con representaciones parciales del mismo tipo. La recurrencia de estos motivos en numerosos objetos quizás responda a que estos símbolos asociados al agua y la fertilidad formaron parte de los atributos propios de la identidad local, que debieron articularse con los mensajes emitidos por el Estado para lograr la legitimación de la dominación a través de un lenguaje compartido (Otero, 2017). Las placas circulares de metal pudieron funcionar como emblemas de poder e identidad, tal como se ha propuesto para otros objetos (Nielsen 2007a y b). El tipo de acanaladura y sostén que presentan en su mayoría indicaría que estos discos estuvieron enastados para ser exhibidos en altura, posiblemente reflejando la luz solar. Entre el conjunto de placas, dos de ellas, confeccionadas en aleaciones de oro, plata y bronce, presentan grabadas las imágenes de dos serpientes dispuestas de forma espejada. El cuerpo se encuentra decorado por líneas paralelas, atributo que comparten con algunos pucos cerámicos que presentan un espiral en su interior segmentado también por líneas dispuestas de forma equidistante (Figura 5).

En los pucos de cerámica, tanto en las paredes internas como externas, las representaciones de los ofidios pueden ser variadas. La mayoría de las figuras espiraladas están rellenas de mallas reticuladas, que pudieron simbolizar las escamas de los ofidios. El reticulado negro sobre rojo, que en determinadas piezas viró al morado, es uno de los elementos decorativos más frecuentes de la alfarería de la última época prehispánica de la quebrada de Humahuaca. Durante el relevamiento de más de 500 piezas cerámicas del Pucará, pudimos distinguir que un gran número de vasijas decoradas presentan diferentes motivos rellenos por reticulados. Algunos motivos, 


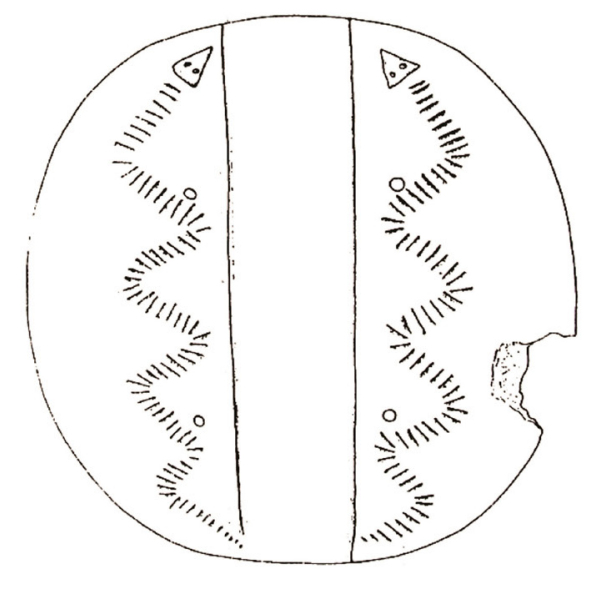

a

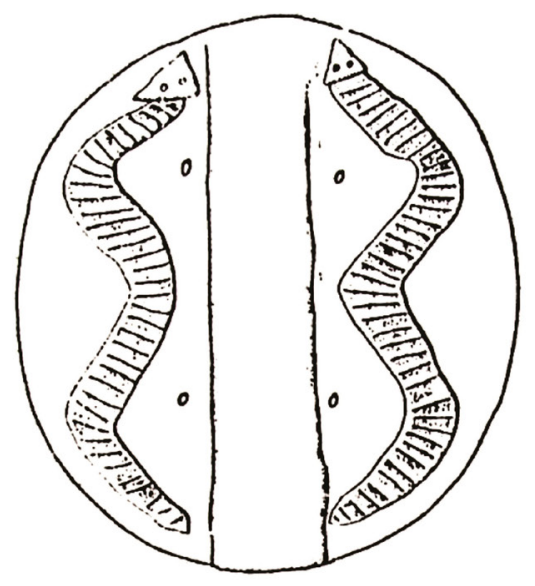

b

Figura 5. Placas de metal con representación serpentiforme, recuperadas en el Pucará de Tilcara: a) disco de aleación de plata y cobre (MEJBA 6009), b) disco de oro (MEJBA 6001).

Dibujos tomados de González (1992, lám. 22).

como los arriñonados conectados entre sí, o las bandas paralelas (Figura 6a, e y f) pareciera que representan los dibujos de la piel de ofidios comunes en el noroeste de Argentina como la Yarará Grande (Bothrops alternatus), la Culebra Andina (Tachymenis peruviana) (Figura 6h), la Falsa Coral (Oxyrhopus rhombifer) (Figura 6g) o la Víbora de Cascabel (Crotalus durissus) (Figura 7c). Los colores con los que se decoraron las cerámicas también podrían hacer referencia a esta última especie. Para reforzar esta idea, es válido mencionar que la versión más explícita de las representaciones de ofidios aparece en tres vasijas abiertas que presentan un espiral reticulado en su interior. En uno de ellos, el espiral termina en una lengua bífida (Figura 6b). En el segundo caso, finaliza en un apéndice que podría simular la cabeza de la serpiente (Figura 6c). En otra pieza cerámica, una fuente Humahuaca Inca N/M (MEJBA 3310), se distinguen varios motivos serpentiformes reticulados, en los que la cabeza del animal aparece en alto (figura 6d).

El espiralado es una figura que se comparte con otros objetos, principalmente los confeccionados en hueso. Se trata de campanas o pabellones de supuestas trompetas, que en su mayoría fueron confeccionados con huesos largos de camélidos, como húmeros. Hasta el momento, en el Pucará solo detectamos un ejemplar elaborado con un hueso humano. En ocasiones, estas "trompetas" estuvieron enmangadas mediante resina a otros elementos de hueso. En su interior algunas de ellas presentan restos de pigmento rojo. De allí que no se deba plantear que únicamente formaron parte de instrumentos musicales, tal como tradicionalmente se ha propuesto (Debenedetti, 1930; Salas, 1945; Marengo, 1954; Lafón, 1956/1957). Pérez Gollán y Gordillo (1993) proponen que pudieron ser utilizados para inhalar polvos alucinógenos. Otra alternativa, señalada por Nielsen (2007b, p. 18), surge a partir de su utilización como "armas" de guerra. Más allá de su función para producir sonidos, pudo tratarse de objetos que evocaban la destrucción de los enemigos y aseguraban la prosperidad de la propia comunidad al formar parte de ritos propiciatorios como emblemas de autoridad (Martínez Cereceda, 1995, pp. 188189). De manera más reciente, Gudemos (2009) sostiene que este tipo de pabellones de hueso formaron parte de instrumentos musicales, a diferencia de una propuesta previa en la que los 

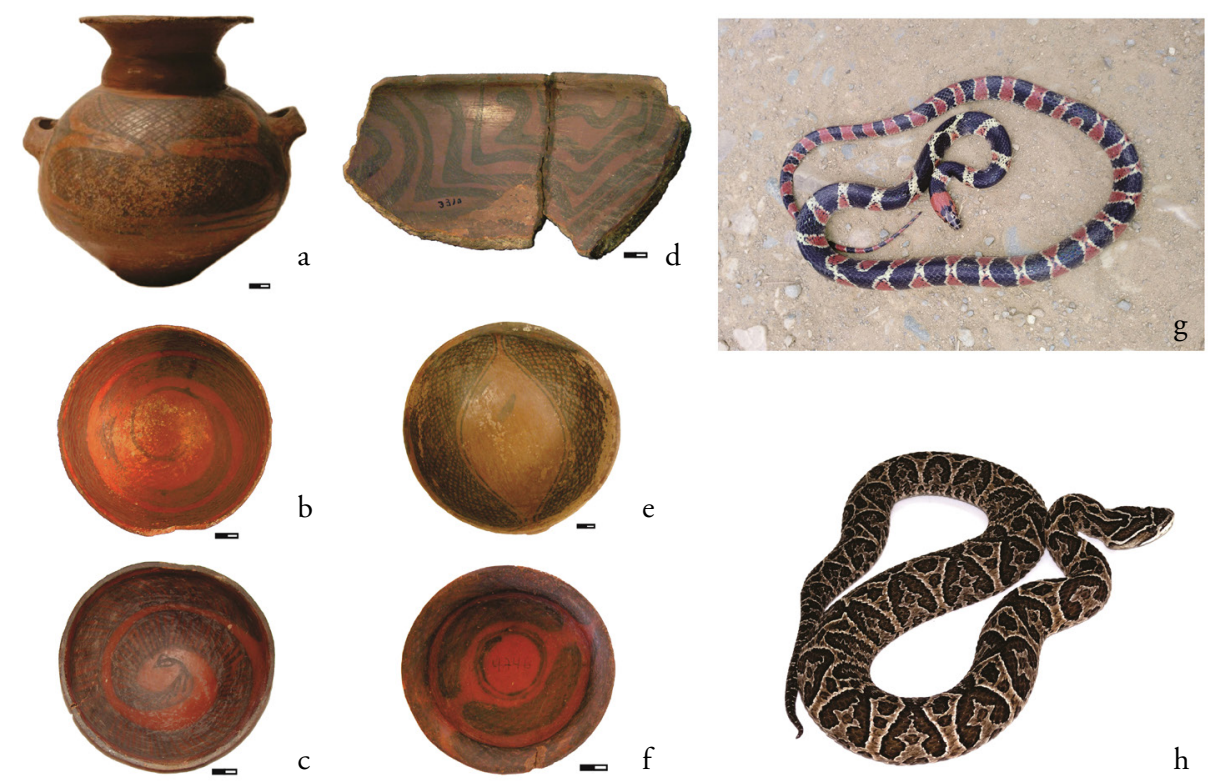

Figura 6. Piezas cerámicas estilo Humahuaca Inca con representaciones serpentiformes: a) cántaro (MT 2247), b) puco (MT 2419), c) puco (MT 2153), d) fuente (MEJBA 3310), e) puco (MT 2191), f) puco (MT 2577), g) ejemplar de Falsa Coral (Oxyrhopus rhombifer). Fotografía de Mauricio Akmentins, h) ejemplar de Yarará Grande (Bothrops alternatus). Fotografía de Nicolás Pelegrin.

describía como cubiletes, ya que consideraba que no había evidencia acerca de su función musical (Gudemos 1998, p. 81). En el Pucará, estas piezas generalmente se hallan en entierros, lo que dificulta no solo su determinación funcional sino también su contextualización temporal, considerando la sucesión de inhumaciones reconocidas en algunas estructuras mortuorias (Otero, Bordach y Mendonça, 2017). En estos contextos, las trompetas suelen aparecer como acompańamiento mortuorio de adultos junto a tabletas para inhalar alucinógenos. En algunos casos estas inhumaciones se pueden asignar temporalmente a momentos preincaicos, en otros se las ha recuperado asociadas a objetos de clara filiación inca, como tupus, platos ornitomorfos, illas o keros. Estas asociaciones podrían indicar una clara continuidad en su uso.

En relación a la decoración serpentiforme de las trompetas, en un ejemplar de $17 \mathrm{~cm}$ de largo confeccionado con un húmero de camélido (MT 2180), se reconocieron dos figuras grabadas en espiral (Figura 7a). El extremo de la cola de una de estas figuras se encuentra relleno por líneas paralelas rectas, mientras que la parte media y superior del cuerpo presenta reticulado. La segunda figura no posee decoración interna. No obstante, dos rombos encadenados sirven para destacar la cabeza del animal. La representación de dos figuras espiraladas juntas podría evocar la lucha entre crótalos durante la época de apareamiento, en la que los machos se enroscan entre sí y se golpean hasta abandonar la pelea (Williams, 1988). Otro húmero de camélido de $15 \mathrm{~cm}$ de largo (MT 2177) tiene grabado una banda reticulada serpentiforme en ambas caras (Figura $7 \mathrm{~b}$ ). Al igual que para el caso de la representación de las serpientes registradas en algunos pucos N/R, solo se dibujó la cola del animal. Alrededor de la banda serpentiforme presenta numerosos círculos con un punto central y en el extremo más ancho, dos triángulos reticulados enmarcados por un rectángulo. 


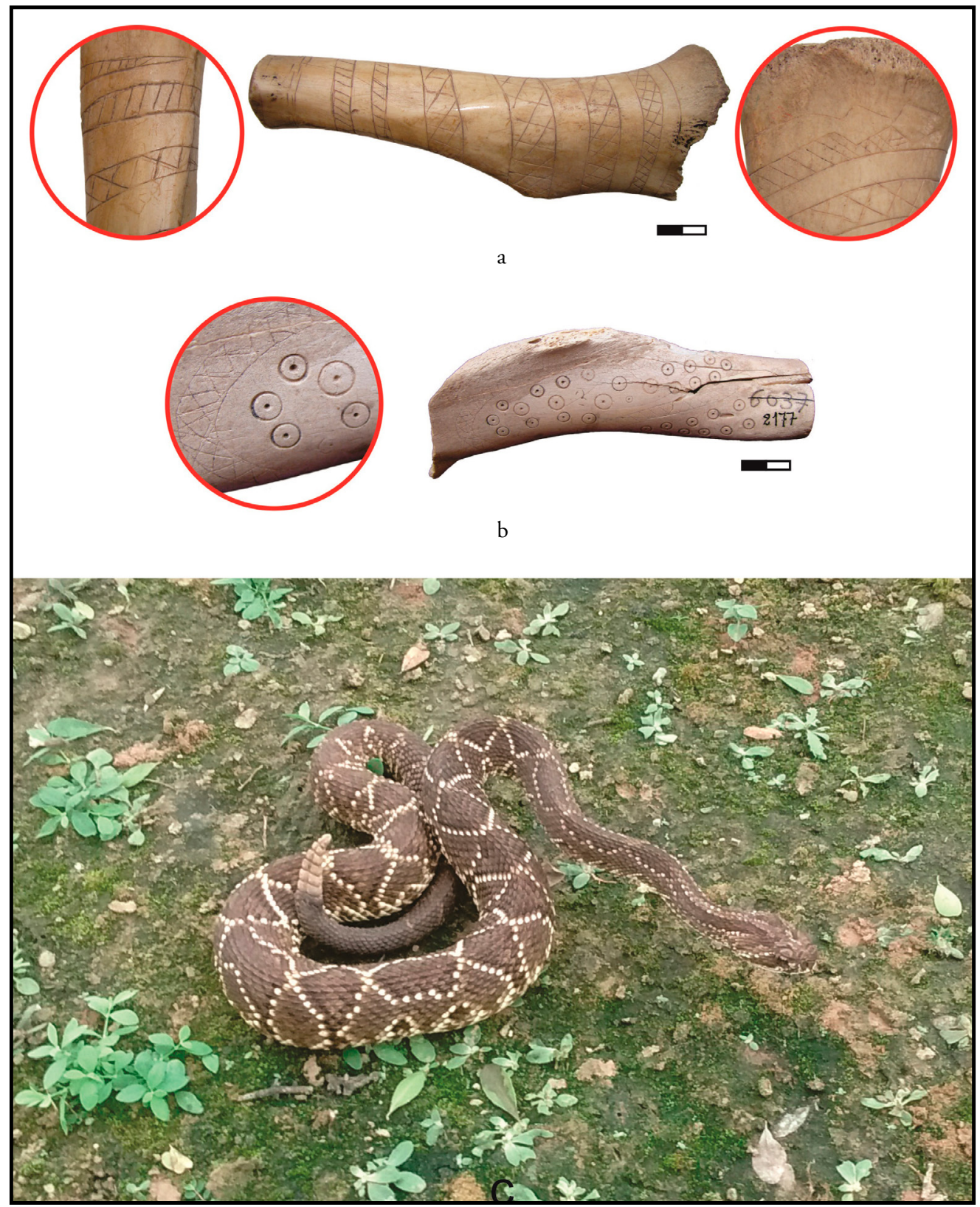

Figura 7. Húmeros de camélido grabados con bandas serpentiformes reticuladas: a) ejemplar MT 2180 y detalle de las representaciones realizadas en los extremos de los espirales, b) pieza MT 2177 y detalle de los grabados de círculos con punto central, c) ejemplar de Víbora de Cascabel (Crotalus durissus). Fotografía de Eduardo Etchepare.

El motivo de círculo con punto central tuvo una amplia dispersión en los Andes. Si bien se lo vincula al moteado de los felinos, Cereceda (1987) plantea que los círculos grabados en un dado moderno publicado por Nordenskiöld (1930), similares a los que detectamos en los objetos del Pucará, se asemejan a los "Ojos de Imaymana" del altar de Santa Cruz Pachacuti Yamqui. Fink (2001, p. 15) los describe como parte de los componentes simétricos de este dibujo que se vinculan con "los ojos de toda la clase de cosas". A su vez, propone para su 
análisis los múltiples sentidos que se desprenden del vocablo "ojos" en las lenguas quechua y aymara. En ambas lenguas principalmente se relacionan con la idea de la esencia y el origen de la vida, o como granos con capacidad germinativa. Al encontrarse en el espacio subterráneo del dibujo de Santa Cruz Pachacuti, representarían el origen profundo de la flora y la fauna. Si esta interpretación sobre su significado es correcta, en el caso de las "trompetas", estos motivos, que en ocasiones se representaron junto a los serpentiformes, quizás se utilizaron para evocar el poder activo de seres vinculados con el mundo de abajo, el ukhu pacha. Más allá de estas hipótesis, es notoria la reiteración con que se plasmaron en diversos objetos y elementos de la naturaleza, tanto del mundo vegetal como animal. En otras "trompetas" se registró el grabado de reticulados en bandas rectas y dameros (Figura 8b). Estos motivos también se reconocieron en otros soportes, tales como tejidos y platos cerámicos ornitomorfos, que en algunos casos representaron aves asociadas a fuentes de agua (Figura 8a). De igual modo, la composición de estos diseños pudo referir al diseño de la coloración dorsal de ciertas culebras, como la Culebra Andina, Tachymenis peruviana (Figura 8).

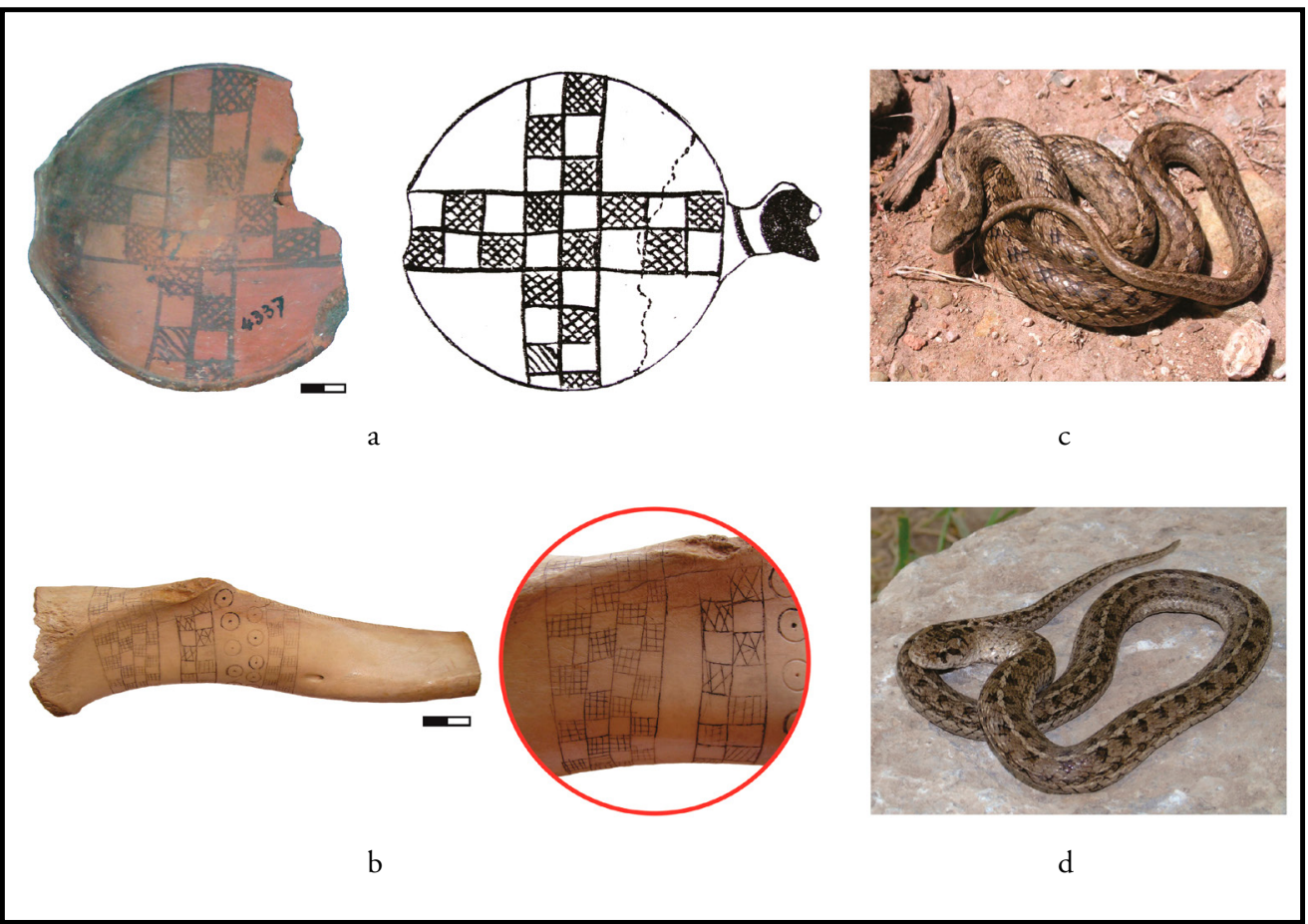

Figura 8. a) plato ornitomorfo (MEJBA 4337) y dibujo tomado de Bregante (1926, p. 293, fig. 352),

b) húmero de camélido grabado MT 2281 y detalle del diseño tallado, c) ejemplar de Culebra Andina (Tachymenis peruviana) proveniente del sur de Bolivia. Fotografía de Arturo Muñoz, d) ejemplar de Culebra Andina (Tachymenis peruviana) proveniente del noroeste de Argentina. Fotografía de Mario Ruiz Monachesi.

Una pieza única entre el conjunto cerámico del Pucará es un aríbalo Cusco Polícromo Figurativo (Figura 9a), recuperado en un edificio que por sus características arquitectónicas y el tipo de objetos de marcado prestigio social, como cerámica Inca Provincial, Inca Paya y otras piezas de origen no local, debió ser ocupado por representantes del Estado (Otero, 2015). Los motivos que forman parte de las tres bandas horizontales del cuerpo de este aríbalo corresponden a figuras de animales presentes en hábitats acuáticos altoandinos. En las dos primeras bandas se 
dibujaron cangrejos del género Aegla. Estas figuras se encuentran rodeadas por motivos de "S", "C" o semiespirales, algunos de los cuales se colocaron sobre las líneas del contorno. La tercera banda, más ancha que las anteriores, está compuesta por 15 insectos del orden Megaloptera y el mismo relleno de $\mathrm{S}$ o $\mathrm{C}$ que en los casos anteriores, aunque en algunos sectores se identifica el motivo de "E" con espirales en sus extremos. A estos últimos, Ambrosetti los llamó signos de lluvia de tres líneas horizontales (Zaburlín y Otero, 2014). Salas (1945) consideró errónea esta denominación, sin aportar más datos sobre su interpretación. No obstante, las asocia a la cultura incaica y menciona la posibilidad de que se vincularan con el contacto hispano-indígena a partir del hallazgo de una vasija que presenta estos motivos junto a un molar de caballo en un sepulcro de La Paya (Ambrosetti, 1902). Lo mismo plantea para los objetos recuperados en el Pucará de Tilcara, dadas las evidencias de contacto detectadas en este sitio (Salas, 1945). Calderari (1991, p. 153) señala que podrían corresponder a la representación de letras vistas por los indígenas en los primeros momentos de contacto. Más allá de estas interpretaciones, los atributos estilísticos de este aríbalo son propios de la cerámica cusqueña, tal como se observa en las piezas presentadas por Pardo (1939). Es posible que los motivos zoomorfos circularan en diferentes regiones; como se registra en la cerámica Ica Inca (Menzel, 1976). Asimismo, existen referencias etnohistóricas acerca del uso de keros y cerámicas que presentaban elementos figurativos que evocaban a lagartos, culebras, víboras y mariposas. Bartolomé Álvarez (1998 [1588]) menciona que estas piezas eran exhibidas en rituales adivinatorios y propiciatorios de fertilidad.

Por último, entre las representaciones registradas en los objetos del Pucará que también pudieron estar vinculadas con estos ritos, detectamos una espátula de hueso con una cara reticulada y

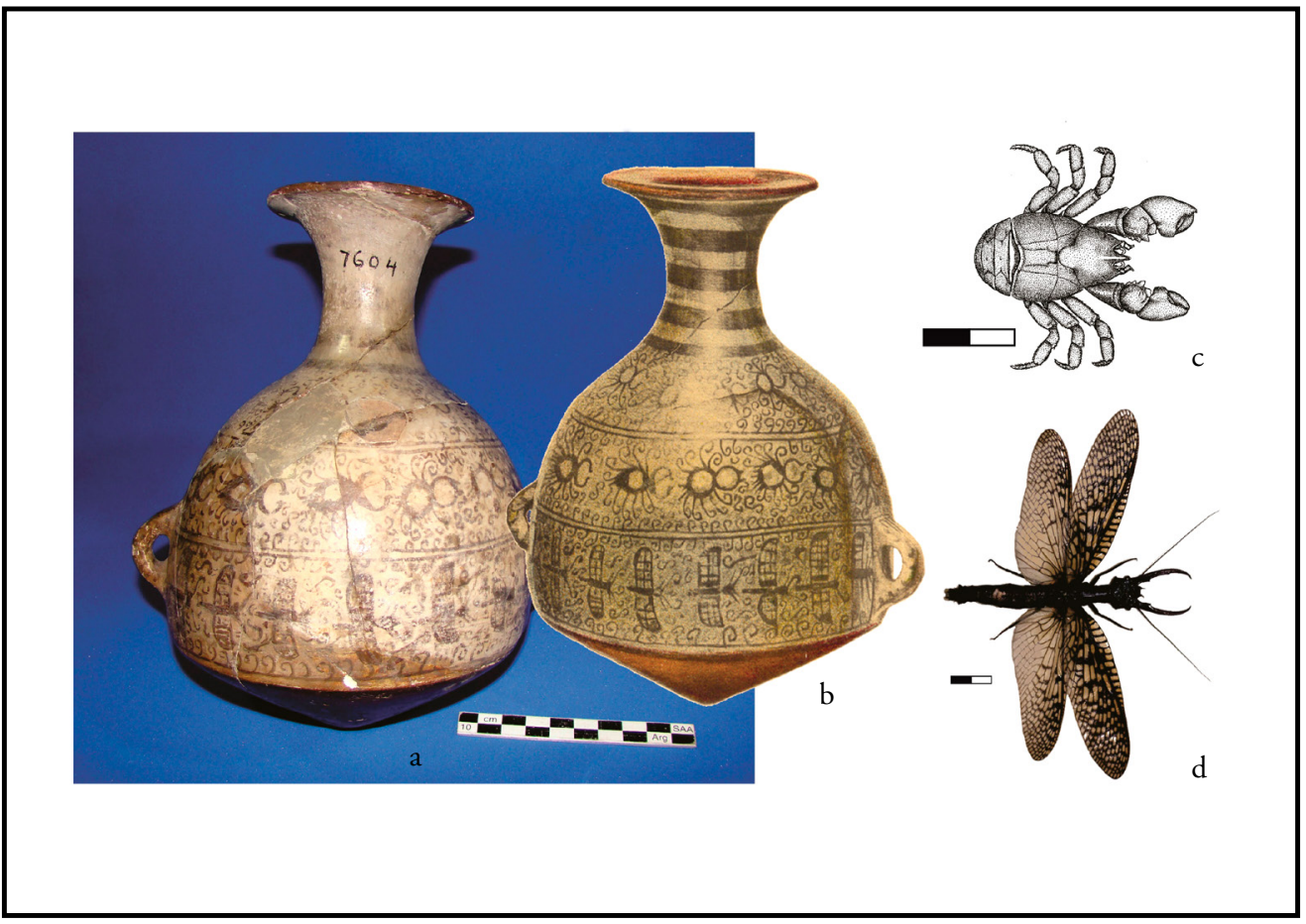

Figura 9. a) Aríbalo Cusco Polícromo Figurativo (MEJBA 7604), b) acuarela realizada por Martín Jensen, tomada de Debenedetti (1930: lám. XIX), c) dibujo esquemático de cangrejo del género Aegla, d) imagen esquemática de un ejemplar macho de Megaloptera. 
la imagen de un cérvido grabada en la otra (Figura 10). En los Andes, los venados son considerados animales potencializadores de la fertilidad, que forman parte del sistema de ordenación del mundo agrícola (Gutiérrez Usillos, 2002). En la iconografía Mochica, los ciervos junto a los jaguares y las serpientes, aparentemente conformaban una fuerte trilogía, dibujada para manifestar la inmortalidad, el poder y la autoridad absoluta. Se los representaba ejecutando acciones humanas en escenas de danzantes y músicos (Golte, 2015). El antropomorfismo de los animales fue un fenómeno panandino, que en el Pucará se manifiesta hasta en el tratamiento de sus restos como si se trataran de restos de seres humanos.
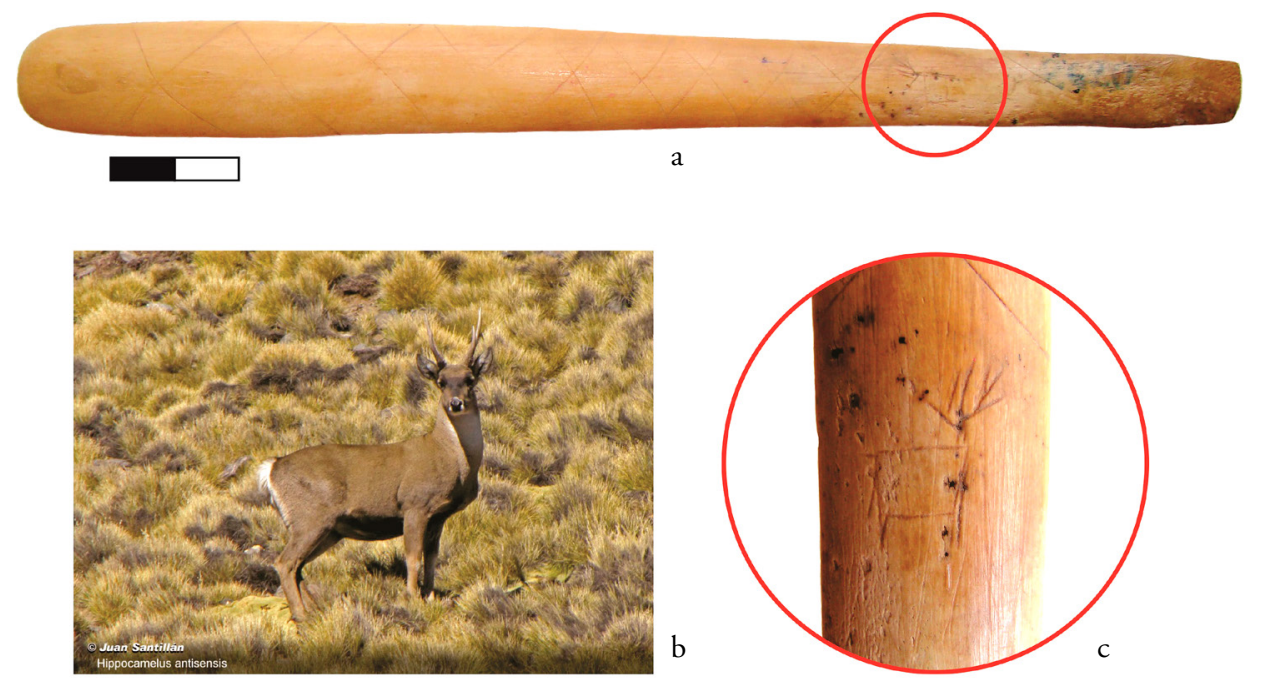

Figura 10. a) espátula para inhalar alucinógenos con grabado de motivos reticulados (MT 2620),

b) ejemplar macho de Taruca (Hippocamelus antisensis) (fotografía obtenida de la página web del SIB APN: https://sib.gob.ar/especies/hippocamelus-antisensis), c) detalle de una figura de cérvido.

\section{El cuerpo de animales que habitaban el cielo y la tierra}

En el medio andino todo tiene vida. Lo material e inmaterial es indisoluble, el presente y el pasado convergen y coexisten en un mismo plano, y el cuerpo y el espíritu de los seres transmutan en constante unidad (van Kessel, 2006; Allen 2015). Así, cuando una persona fallece, si bien abandona la corporalidad, no muere jamás. Esto genera una expectativa entre los allegados al difunto, ya que la o el fallecido se convierte en un medio para interactuar con las entidades que habitan otros planos. Haciendo valer el vínculo de familiaridad, se les pide protección, beneficios inmediatos e intercesión sobre el destino de los vivos. En el pasado prehispánico, a medida que el cuerpo de los difuntos con un estatus particular se transformaba, llegó a adjudicársele más poderes, atributos y/o valores de los que tenían en vida. Su lado material, representado por el cuerpo o una parte de él, se cargaba de significados y agencia, dando aún mayor potencia al conjunto de ancestros. Lo mismo sucedía con los restos de determinados animales. 
En el Pucará de Tilcara, la manipulación de los cuerpos o partes esqueletales no fue exclusiva de los humanos. La separación intencional de los cráneos también se registró en animales que acompañaban a los difuntos o que simplemente se conservaban en espacios habitacionales. Sus cabezas, al igual que para el caso de las personas, pudieron representar la inclusión o la presencia de todo el animal. Con su incorporación posiblemente se buscó sostener aquellos atributos que caracterizaban a cada especie y que querían ser apropiados simbólicamente por las personas. En este sentido, los cráneos pudieron retener la fuerza y las habilidades de ciertas bestias para usarlos en beneficio propio, y a su vez, interceder ante cuestiones climáticas por su capacidad para articular los diferentes mundos. Los animales que eran parte del mundo subterráneo, por donde también transitaban los difuntos, permitían unificar valores de vida y muerte, y por lo tanto de fertilidad (Fink, 2001; Steele y Allen, 2004).

Entre los hallazgos del Pucará más representativos de estas creencias se puede describir la detección, en el interior de una olla, del cráneo de un cérvido joven junto a restos de cestas, dos pucos y placas de un edentado. Este hallazgo se produjo en la misma vivienda en la que se encontró el disco de oro con las serpientes repujadas descrita anteriormente (Debenedetti, 1930, p. 51). Más allá de la presencia de este cráneo y el grabado de la figura de un cérvido en una espátula, es frecuente encontrar astas en los contextos de producción metalúrgica y lapidaria de este sitio. Hasta el momento contabilizamos más de 40 ejemplares que posiblemente se utilizaron como herramientas. Tal como se mencionó, los cérvidos fueron animales muy apreciados, siendo protagonistas de diversos mitos (Stelle y Allen 2004; Salomon y Urioste, 2005). Aún, en los Andes centrales son considerados el ganado de los apus (Sandoval Chayña, 2009). Por ello, el uso de sus partes en diferentes escenarios, incluidos los extractivos y productivos, debió implicar la posibilidad de manipular sus poderes mágicos para la reproducción de los recursos. Las astas también pudieron usarse en las canteras como picos para extraer rocas blandas y otros minerales. Más adelante, se retoma la idea que existieron numerosas creencias en torno a la regeneración de las vetas.

En una cámara cilíndrica localizada en otra vivienda, que contenía el esqueleto de una persona adulta y un cántaro utilizado como urna para la inhumación de dos niños pequeños, se recuperó una gran pieza decorada que conservaba seis cabezas de puma (Debenedetti, 1930, p. 48). En otro recinto se encontró una olla con el cuello intencionalmente seccionado. En su interior habían sido colocados dos nińos, un puco negro, una "trompeta" de hueso y el cráneo de otro felino (Debenedetti, 1930, p. 87). En el interior de otra cámara cilíndrica, que no presentaba inhumaciones humanas, se hallaron el cráneo de un puma junto a restos de madera, tejidos de paja, cerámica y una boquilla de hueso, que pudo formar parte de las anteriormente mencionadas trompetas (Debenedetti, 1930, p. 67). En otro contexto, al que pudimos caracterizar como una casa-taller ocupada durante la dominación incaica, se recuperaron colmillos de puma (Figura 11). Los grandes felinos se asociaban principalmente a la prosperidad, al poder y a los ritos de pasaje entre este mundo y el ukhu pacha (Salamon y Urioste, 1991; Steele y Allen, 2004; García Escudero, 2009). Esta capacidad para la transición era compartida con el zorro, quien por aparecer cuando caía el sol, a su vez se relacionaba con la transformación del día en noche. De allí que las pieles u otras partes de estos animales fueran muy requeridas. En el Cusco, los ritos de pasaje a la adultez de los varones nobles durante el Capac Raymi concluían ataviando a los jóvenes con pieles de puma (Garcilaso de la Vega, 1609; Cobo, 1653). Zuidema (1985), a partir de la iconografía de algunos keros, utilizados en ritos de carácter político, se aventuró a reconocer una asociación metafórica entre la cola de los pumas, representados en estos vasos, y el agua como agente fertilizador. 

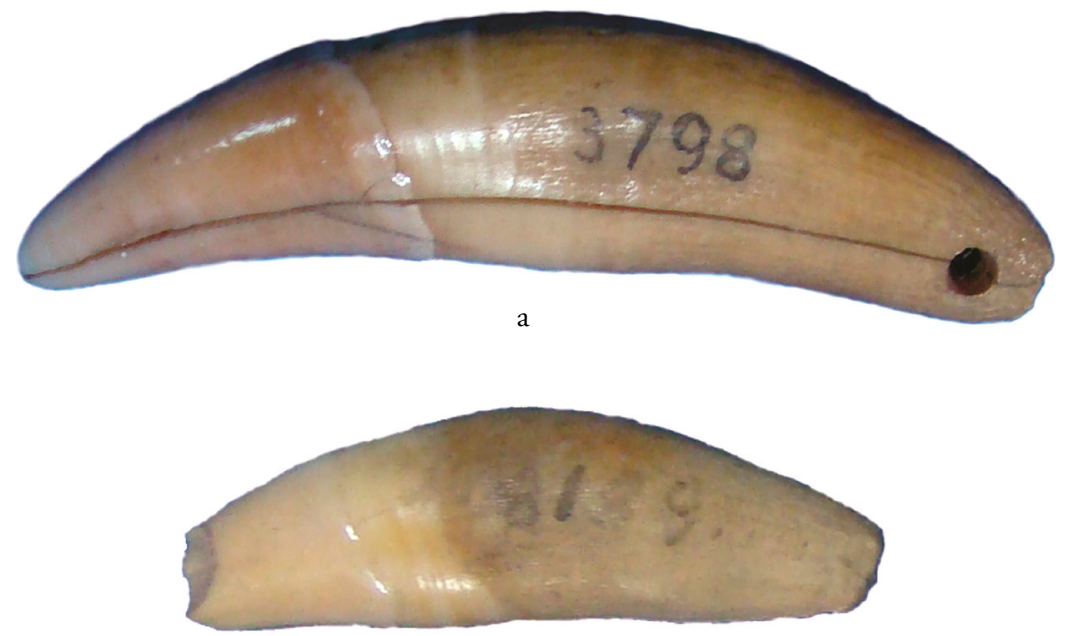

$\mathrm{b}$

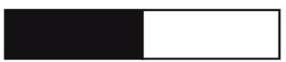

Figura 11. Colmillos de puma (Puma concolor): a) MEJBA 3798, b) MEJBA 8189.

El cóndor fue otro de los animales sagrados y propiciatorios de fertilidad que formaban parte del $u k h u$ pacha. Era considerado guardián de la luz y por su vuelo a gran altura se lo asociaba a los picos de las montañas (Steele y Allen, 2004). Los cerros y sus nieves estacionales también cumplían un importante rol como agentes fertilizadores. El deshielo de los picos, el cual generaba cursos de agua o un mayor caudal, fue sin dudas otro demarcador de los ciclos estacionales (Sanhueza, 2005). Para el Pucará, Debenedetti (1930, pp. 69-69) menciona el hallazgo de un esqueleto de cóndor completo en el interior de una de las cuatro cámaras cilíndricas construidas en un recinto, al que denominó Casa de los Brocales (Figura 12). En la misma cámara donde apareció el cóndor encontró un puco de asa lateral, un vaso alto y una fuente decorada geométricamente; en la cámara contigua se recuperaron los esqueletos de dos personas adultas, fragmentos de utensilios de madera, un asta de ciervo y una espátula de hueso. La inclusión de ofrendas mortuorias junto al cóndor podría indicar que fue sepultado siguiendo las mismas prácticas funerarias que en el caso de los humanos. Lo mismo puede estimarse para los pumas sepultados en las cámaras que no presentaban restos óseos humanos.

Las grandes aves, al igual que los felinos, fueron símbolos de jerarquía social entre los incas. Guaman Poma de Ayala (2006 [1615], p. 111) remarca este concepto a través de la figura de la Séptima Colla, al mencionar que criaba pequeños pájaros, palomas, loros y guacamayos. Entre las sepulturas del Pucará es frecuente encontrar el entierro de personas junto a aves, o la colocación de cráneos de loros al interior de las vasijas (Debenedetti, 1930, pp. 61, 74). El caso más extraordinario corresponde a una pieza cerámica modelada para simular la figura de un loro (Figura 13), que en su interior conservaba el cráneo de un ave psitaciforme. Junto a esta pieza se hallaron fragmentos de platos ornitomorfos. La diversidad de representaciones en este tipo de platos, hallados en los sectores más elevados del Pucará, merece un estudio pormenorizado de las especies que se quisieron recrear, ya que aún hoy en distintas comunidades 


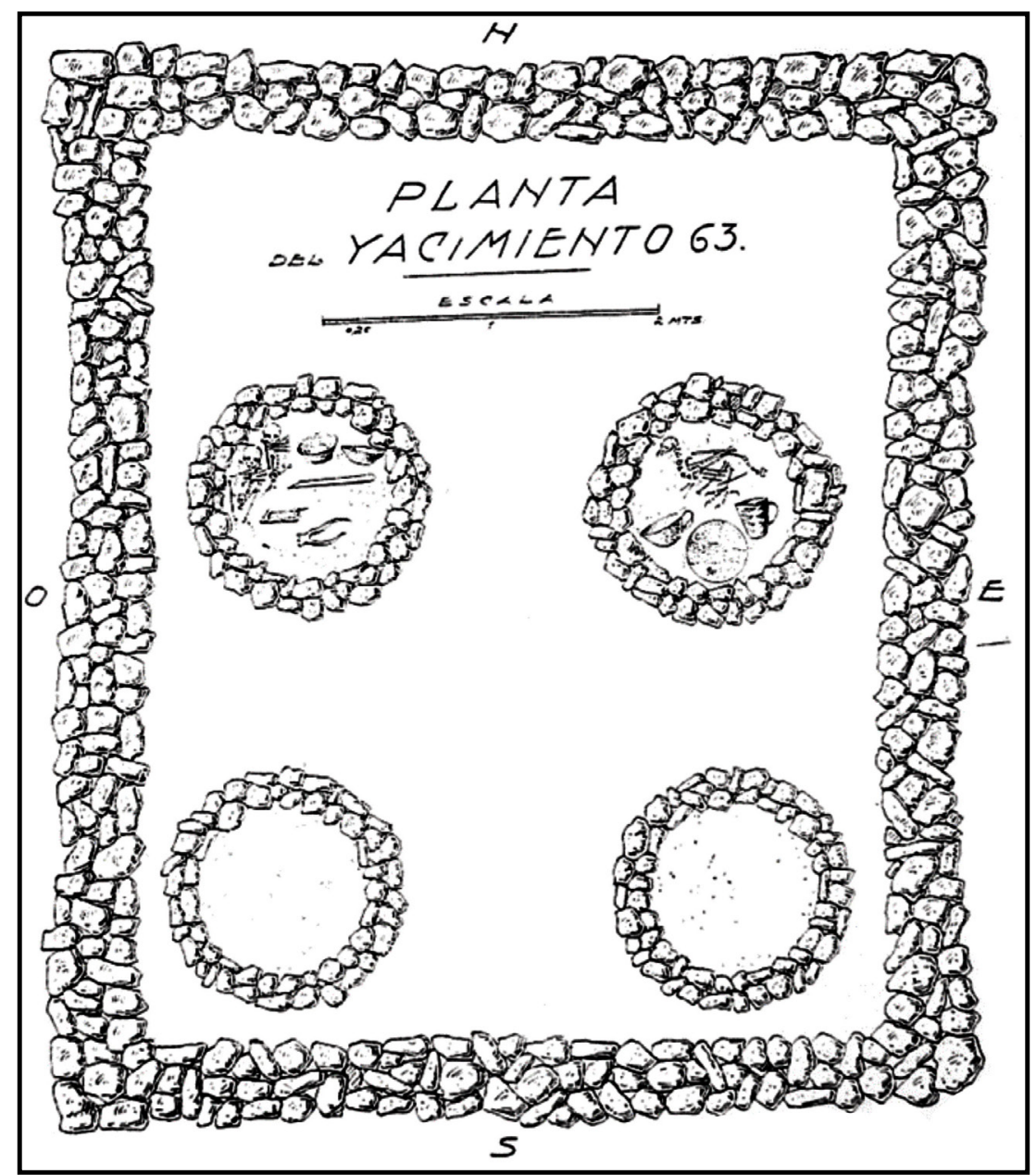

Figura 12. Planta de la Casa de los Brocales. Tomada de Debenedetti (1930, p. 69).

andinas se considera que el comportamiento de las aves está ligado a las condiciones meteorológicas y los ciclos estacionales. Es de estimar que su veneración también haya sido parte del sistema de creencias para estimular las fuerzas reproductoras de la tierra. Los nombres de algunos miembros jerárquicos del Estado incaico eran designados a partir de la denominación de las aves. Esta práctica no fue exclusiva de los Andes centrales. Para el caso de la quebrada de Humahuaca, el nombre de Viltipoco, quien fuera el líder de la rebelión antiespañola, evoca las cualidades de un ave de presa. Sánchez y Sica (1998, p. 184) sugieren que este nombre, específicamente la raíz “vilti”, siguiendo los diccionarios kunza, pudo significar 'águila o halcón' (San Román, 1890). Esta definición se encuentra presente también en otras compilaciones (Vilte Vilte, 2004). Asimismo, Sánchez y Sica agregan que el uso de este nombre pudo responder a la figura de un líder capaz de estrechar alianzas para unir territorios y pueblos, evocando la capacidad de vuelo de estas aves para atravesar grandes extensiones como si fueran una. Estas virtudes pudieron reflejar la investidura de Viltipoco, de presunto origen atacameńo, considerado el último representante de los Incas previo a la llegada de los europeos. El uso de esta denominación quizás esté involucrando la capacidad de transmutación de la figura humana en animal. Es decir, en el equilibrio de las relaciones recíprocas no solo se daba el antropomorfismo de las especies animales, sino también el zoomorfismo de los humanos. 


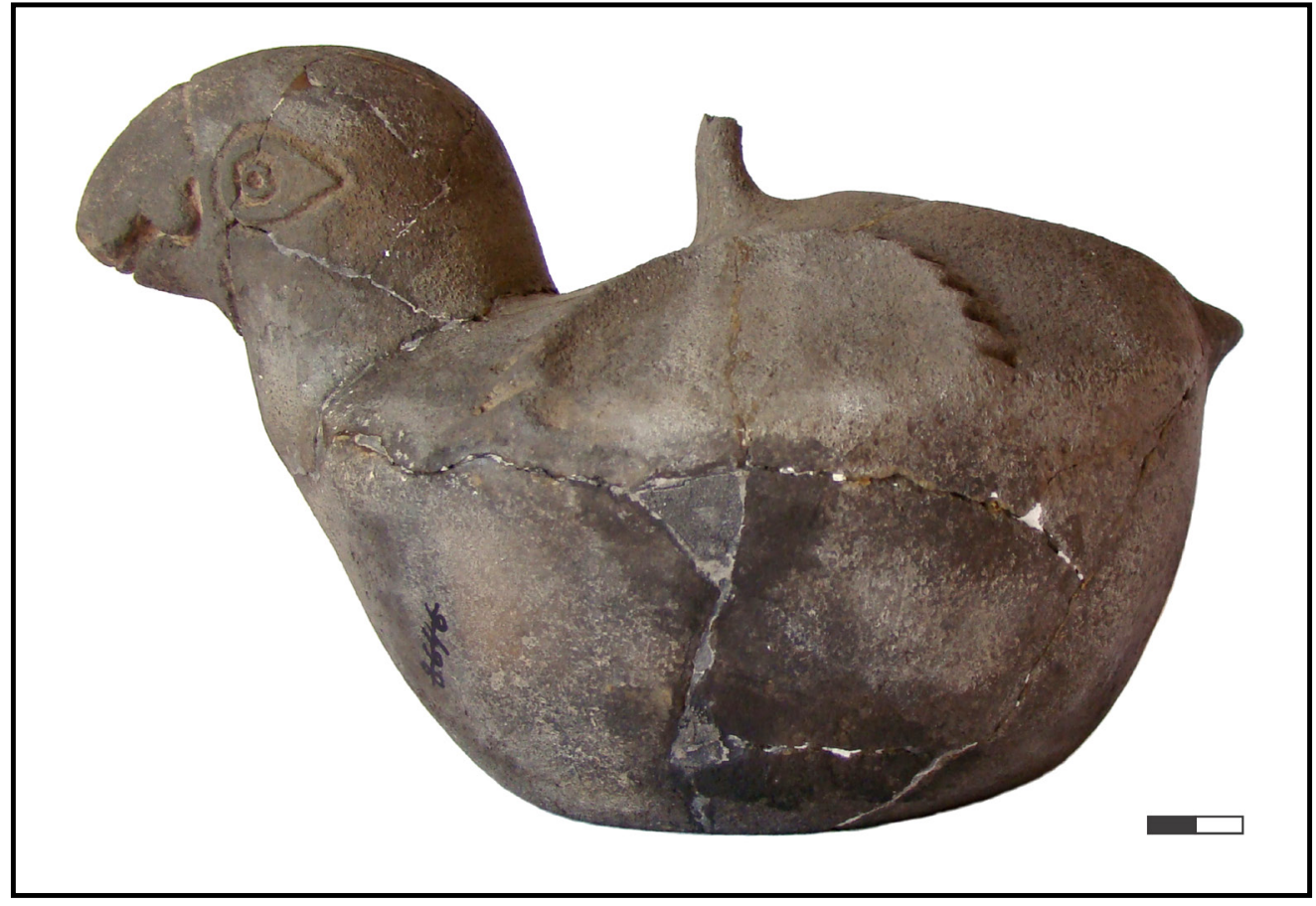

Figura 13. Vasija modelada, Museo Arqueológico “Dr. E. Casanova”, FFyL-UBA. Pieza MT 2555.

Otro ejemplo más reciente se desprende de los resultados de nuestras excavaciones en la cima del Pucará. En la Estructura 7 del Sector Z se halló el cuerpo de una mujer adulta de aproximadamente 30 años de edad, fallecida a fines del Período Incaico o inicios del Período HispanoIndígena (primera mitad del siglo XVI DC.: $1642 \pm 27$ AD, Número e identificación del Laboratorio: D-AMS 028343) (Figura 1b). A partir del estudio de la fauna cadavérica se pudo determinar que esta mujer no fue sepultada, sino expuesta a nivel superficial, sentada sobre el piso arcilloso de un patio (Otero, Centeno, Fuchs, Gheggi y Seldes, 2019).

Entre las ofrendas depositadas se detectaron numerosas piezas cerámicas, tales como un plato ornitomorfo, una ollita decorada en N/R, un puco que contenía una pata delantera de camélido, dos placas de oro y restos de zea mays, y otro puco con el interior decorado, justamente por una figura espiralada como las anteriormente descritas, que conservaba restos de vegetales carbonizados entre los sedimentos de su relleno (Lopez Geronazzo, Musaubach y Otero, 2019) (Figura 14a). La representación completamente espiralada de la figura interna de este puco podría indicar que se buscó dibujar a una serpiente y no a una culebra. Entre los criterios de diferenciación entre corales y falsas corales, las primeras suelen presentar la cola más corta y enrollada que las víboras no venenosas (Williams, 1988).

Asociada a estas ofrendas mortuorias se encontró la mandíbula de un posible espécimen doméstico de Cuy (Cavia Porcellus) (Lopez Geronazzo, Otero, Álvarez, Ercoli y Ortiz-Delgado, 2019). La presencia de esta especie en el Pucará, muy poco estudiada en la Argentina, podría estar relacionada con el proceso de conquista incaica de la quebrada de Humahuaca. A pesar de que en los Andes centrales este animal estuvo presente en variadas prácticas prehispánicas, su hallazgo en Tilcara se plantea como un caso único en la región, resaltando su significado entre los incas de las provincias. En las crónicas, el consumo de cuyes figura como uno de los 
alimentos rituales más destacados (Ramírez, 2005). Por otro lado, en el sector del abdomen de la mujer se encontraron huesos de una extremidad anterior, radio, ulna y metacarpales, de un lagarto de la familia Teidae (posiblemente Salvator merianae o Teius teyu). Estas especies no habitaban en la quebrada de Humahuaca, por lo que se estima que este ejemplar quizás se trajo desde la ecorregión chaqueña (Figura 14b). Por su ubicación, quizás fue colocado entre la vestimenta o mantas del fardo funerario. Para las actuales comunidades aymaras, los lagartos tienen poderes curativos. Se utilizan para minimizar dolores producidos por artritis o infecciones bucales. En el caso de este hallazgo, quizás su inclusión también tuvo un fin medicinal, o como ha sido registrado en Chuquisaca, pudo servir para atraer la fertilidad y favorecer la crecida de las aguas (Sánchez Canedo, Bustamante Rocha y Villanueva Criales, 2016). Otras evidencias que indican una marcada preparación del cuerpo y del contexto funerario, son los ornamentos. En el sector del tórax, esta mujer conservaba numerosas cuentas de turquesa, de hueso y una placa de metal (aleación de oro y plata). A partir del estudio del polen, recuperado entre el sedimento de este sector, se pudo determinar que además estuvo adornada con flores de laureles (Cinnamomum porphyrium; Ocotea puberula) de las Yungas (Méndez, Sánchez, Otero y Lupo, 2019).

Todo parece indicar que el cuerpo de esta mujer estuvo expuesto con el propósito de ser venerada en el marco del culto a los ancestros. La variedad de elementos colocados a su alrededor y la diversidad de animales asociados a su cuerpo podrían indicar que contó con un destacado estatus dentro de la sociedad. En las crónicas se enumera a los cuyes, maíces, camélidos y aves entre los principales alimentos presentes en los eventos de comensalismo y ofrendas a los mallquis (Ramírez, 2005) y apus (Bray, 2015). Durante la preparación de estos actos, los animales, en tanto seres sagrados, debieron ser venerados y tratados de la misma manera que los humanos.

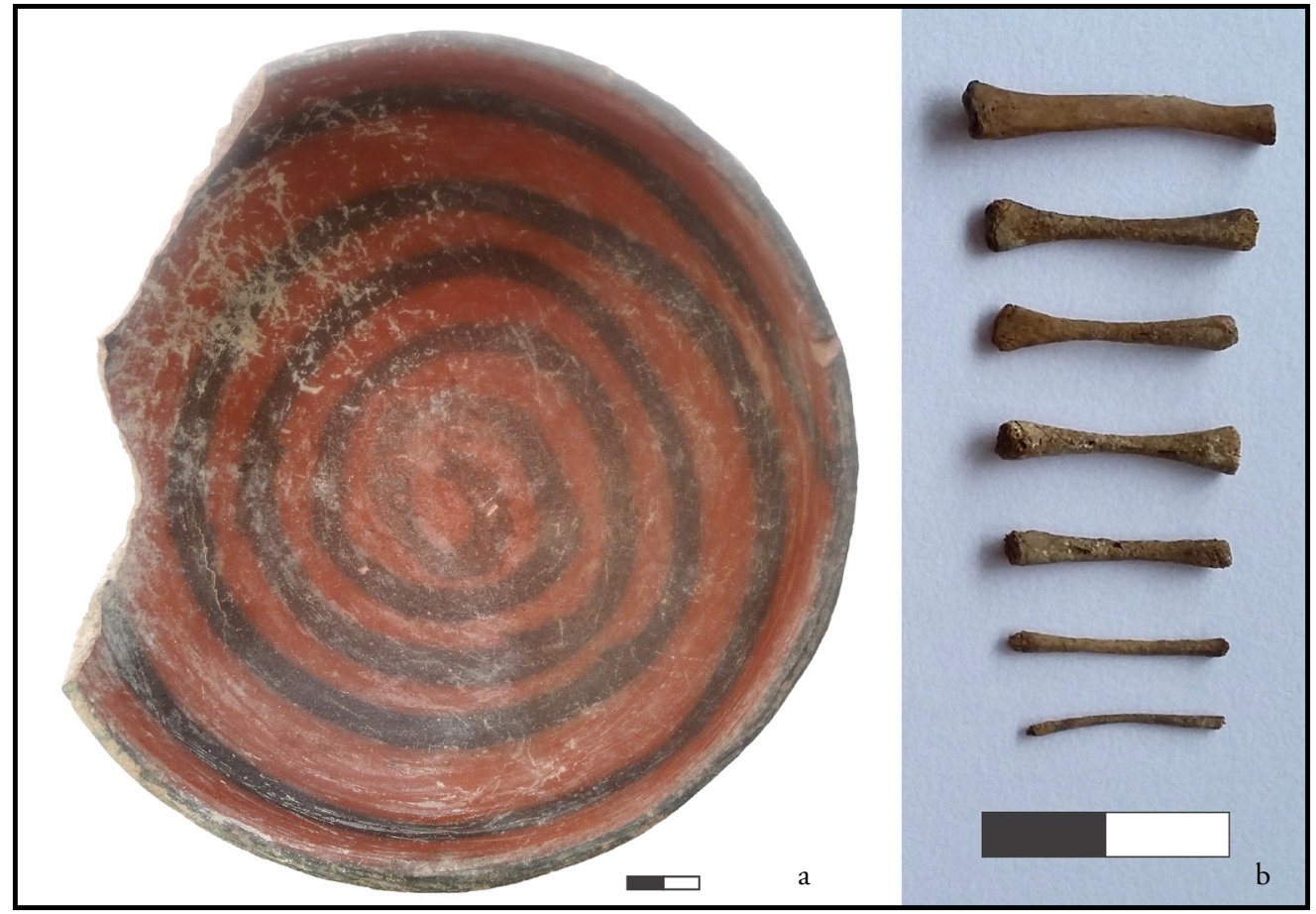

Figura 14. a) puco Humahuaca Inca N/R, con decoración interna de figura espiralada,

b) huesos de lagarto recuperados en el contexto funerario de la Estructura 7, Sector Z del Pucará de Tilcara. 
Su ofrenda y posible ingesta colectiva junto a la mujer fallecida pudo llegar a representar un acto ritual transformador y regenerador de vida.

En Tilcara, estas prácticas continuaron hasta la Colonia. Luego de la Conquista española, diversos sectores del Pucará permanecieron en uso al menos como espacios de enterratorio o como puntos de encuentro para desarrollar ritos que incluyeron animales emblemáticos. Una muestra de esta veneración es el hallazgo del entierro de un esqueleto completo de un bovino que realiza Debenedetti (1930, p. 104). El cuerpo de este animal estaba colocado en una cámara de piedra de dos metros de diámetro tapada con grandes lajas, construida en el centro de un recinto. A partir de la revisión de las colecciones detectamos un puco prehispánico que también fue recuperado en el interior de esta estructura. Es posible que el entierro del vacuno se realizara tiempo después del uso de este recinto como espacio de habitación, cuando ya se había constituido la encomienda y la reducción del pueblo de Tilcara (siglos XVII y XVIII DC). Sánchez (1996) señala que la principal actividad de los únicos encomenderos de la comunidad y encomienda del pueblo de San Francisco de Tilcara entre 1593 y 1776, correspondiente al linaje de los Argañarás y Murguía, fue la actividad ganadera. Dado que los sucesivos encomenderos no se hacían cargo del sustento de sus indios, estos adoptaron rápidamente los cultivos y ganados europeos generando un sistema de producción mixto, en el cual se combinaba la tradición local con la europea (Sánchez, 1996, p. 153). El hallazgo de este esqueleto, por más que se trate de una especie de origen europeo, remarca la persistencia de rituales andinos vinculados con la prosperidad productiva. La sustitución de las figuras veneradas, o más bien su agregación al conjunto de entidades sagradas, demuestra la permanencia de prácticas necesarias para sostener la reproducción cotidiana y la abundancia de los recursos mediante manifestaciones que entrecruzaban lo terrenal con lo mítico y lo cosmológico, y lo local con lo foráneo, sin importar las distancias materiales e inmateriales.

\section{Sintetizando actores y acciones}

En el Pucará de Tilcara, las representaciones zoomorfas en diferentes objetos y el hallazgo de animales en viviendas, edificios ceremoniales y estructuras mortuorias marcan una profunda integración de los mismos en el plano religioso local. La apropiación simbólica de las capacidades de ciertas especies debió fundarse en primera instancia en los atributos vinculados a su ferocidad, camuflaje, capacidad de vuelo, fuerza y poder de envenenamiento. Con el tiempo estas creencias pudieron consolidarse, al punto de convertirlos en seres míticos y hasta cabeza de linajes. Así fueron connotados de poderes activos en el inframundo por su capacidad para percibir los cambios climáticos, injerencia para mediar ante otros ancestros y divinidades, y controlar ciertos fenómenos catastróficos.

En los Andes centro-sur, los principales animales que actualmente marcan la transición de la época de lluvia a la estación seca son los sapos y las serpientes (Bouysee-Cassagne, 1988). También se los asocia a fenómenos astronómicos. La configuración de sus constelaciones coincide con el tiempo de apareamiento de diversas especies, por lo que hasta se han construido calendarios en los que los ciclos agrícolas se encuentran en sincronía con el comportamiento de los anfibios, dada su habilidad para predecir la llegada de las lluvias (Urton, 2005). A las serpientes se las vincula directamente con la Vía Láctea, entidad que contiene a todas estas constelaciones, con el poder de espantar el frío y la enfermedad, y con permitir el normal ciclo de la vida (Sánchez Canedo et al., 2016). Asimismo, en las crónicas figuran diferentes categorías que hacen referencia a la manera en que se clasificaban los anfibios. En todos los 
casos estas categorías estaban ligadas a sus funciones como marcadores temporales. Entre ellas se destaca la mención de Ramos Gavilán (1621), quien describe un rito ejecutado en el lago Titicaca donde asegura "usaban poner sobre unas peñas unos idolillos, sapos y otros animales inmundos, creyendo que con esta ceremonia alcanzaban el agua que tanto deseaban”. Esta visión propiciatoria de los sapos, considerados en algunas comunidades como pachawawa (mellizos e hijos del rayo), podría aludir a antiguas concepciones sobre la estación lluviosa, en referencia al pachatijra o thikharasi pacha (Bouysee-Cassagne, 1988), sinónimo de pachackuti, es decir, "el tiempo de muchas aguas cuando por llover se caen las casas", plasmadas por algunos cronistas, como Bertonio (1603a y b).

Resulta interesante el uso del concepto pachakuti en este contexto, que también pudo estar ligado a su definición como tiempo de renovación, patrones cíclicos y regulares de la historia, que llevan a plantear nuevas eras (Steele y Allen, 2004). También, la noción sobre la filiación con el rayo no es menor. El rayo o Illapa es una de las divinidades más veneradas y respetadas en los Andes, porque si bien el trueno anuncia y trae lluvias, puede causar destrozos a través del granizo y la inundación. Esta divinidad además controla los vientos, el frío y los estallidos volcánicos (Gisbert, 1980; Bouysse-Cassagne, 1988; Montes, 1999). Durante el Tawantinsuyu, Illapa fue venerado en el Qorikancha, junto a las supremas divinidades del Sol y Wiracocha (Fink, 2001; Gisbert, 2001). Su figura relampagueante guardaba una significación directa e imaginaria con la serpiente o amaru (Polo de Ondergardo, 1571). Algunas illas con valores particulares, como los meteoritos o piedras rayo, en la actualidad continúan asociándose a Illapa, bajo la figura del Santo Santiago o Tata Santiago. Entre los aymaras, este Santo aún es representado sobre este tipo de piedras. Por su vínculo directo con el rayo y marca de golpe, pueden ser utilizadas para propiciar las visiones entre los yatiris (Oros Rodríguez, 2015). Vale destacar, y en referencia a nuestro caso de estudio, que existen ejemplares del Tata Santiago representados en bloques de alabastro. Esta variedad de rocas en Bolivia también fue muy aprovechada para confeccionar illas de figuras de ovinos, caprinos y construcciones. El prestigio de este recurso y su uso se registran desde momentos coloniales tempranos en la provincia de Ayacucho, Perú. Para este distrito, Bernabé Cobo en 1626 describe las piedras de Huamanga como pequeńas tallas en fino alabastro muy blanco, extraído de canteras locales (Stastny, 1981). Durante la Colonia, además de usarse para fabricar illas de animales, se utilizaron para recrear pesebres cristianos (Núńez, 1992). De estos ejemplos actuales e históricos se desprende una clara asociación entre las illas, Illapa y las serpientes como elementos del orden religioso en activa articulación, a los que se les podría sumar el alabastro.

Esta asociación sirve para repensar los hallazgos realizados en el Pucará. Tal como se mencionó, una de las principales rocas utilizadas en este sitio para elaborar de manera especializada illas y objetos de uso suntuario fue el alabastro. Frente a este sitio se encuentran buenas fuentes que durante la dominación incaica fueron explotadas intensivamente. Sus vetas blancas se presentan de forma laminada y quebrada, por lo que recuerdan la figura del rayo, contrastante con el fondo rojizo de las arcillitas de la Formación Lumbrera (Larcher, com. pers., 2019). En trabajos previos planteamos que las figuras serpentiformes detectadas en las vasijas cerámicas podrían manifestar rasgos identitarios locales (Otero, 2017). Las representaciones iconográficas en diferentes soportes posiblemente hicieron referencia al repertorio simbólico con el que los tilcaras se identificaban étnicamente. Claramente, este repertorio estuvo enraizado en elementos propios de la naturaleza. Sumando otro aporte a esta idea, es posible sostener que la gran cantidad de representaciones de ofidios podría indicar la necesidad de contar con el respaldo de Illapa, no solo para recibir lluvias sino también para disponer de vetas de alabastro de forma permanente. Este recurso, tan utilizado para producir objetos suntuarios, claramente 
debió tener un alto valor para los incas. En otros trabajos mencionamos aspectos relacionados sobre la similitud de estos objetos con los hallados en algunos sitios del centro cusqueño, como Sacsahuaman y Machu Picchu (Otero et al., 2018a).

En Tilcara, el alabastro al parecer fue únicamente explotado por el Inca. Resulta notorio que, existiendo fuentes en el área, no se tengan evidencias certeras de su aprovechamiento en momentos previos. Solo se cuenta con la referencia de Nielsen (1998), quien encontró un pequeño siku de cinco tubos en Los Amarillos. Para este hallazgo, que representa un ejemplo aislado en la quebrada, más allá de los objetos encontrados en el Pucará, aún no se ha podido determinar su cronología. En el caso de que la producción de objetos confeccionados con esta roca se iniciara masivamente con los incas, su manufactura debió implicar la imposición de una nueva tradición tecnológica y estilística. La transformación de un recurso, que obtenido como roca llegaba a convertirse en finos objetos ornamentales y simbólicos, debió involucrar variadas y nuevas creencias que permitieran justificar su producción a gran escala, amplia distribución y una gran inversión laboral. Como en otros procesos productivos, seguramente esta transformación de los minerales recreó los ciclos registrados en la naturaleza, considerando que muchas líneas del pensamiento económico andino surgían de la alegoría con la vida biológica (Van Kessel, 2006, p. 227; Tarragó, González, Ávalos y Lamamí, 2010). Este pensamiento sostenía que la regeneración de los recursos mineros solo ocurría cuando se veneraban a los cerros que los contenían (Aliaga, 2006). De este modo, se lograba que sus vetas se criaran y reprodujeran de la misma forma en que lo hacían las plantas (Harris y Bouysee-Cassagne, 1988). Estas creencias debieron poner de manifiesto la idea de los ciclos y quizás del pachakuti. En este contexto, las illas de alabastro pudieron formar parte del interjuego de representaciones y significados vinculados con la propiciación y la multiplicación de recursos.

El agua, junto con el sol, fue otra de las entidades ordenadoras del esquema centrado en el culto a la fertilidad, por ser ambos dadores de vida. Es por ello que el aguacero fértil, las vertientes, las nieves en las cumbres y las qochas, al igual que los ancestros, merecían su adoración continua. Los animales asociados a estas wak'as no quedaron por fuera de estas prácticas. Ejemplo de ello son las especies representadas en diferentes objetos o identificadas mediante sus restos esqueletales en el Pucará. El registro arqueológico asignable al período de dominación incaica de este sitio da cuenta de que ofidios, anfibios, reptiles, insectos, crustáceos, moluscos y mamíferos formaron parte de los personajes sacralizados que posiblemente funcionaron para señalar los cambios de estaciones, atraer la fecundidad, beneficiar la abundancia y repeler las inclemencias atmosféricas. Algunas de estas especies se pueden reconocer como parte del kay pacha, pero también del ukhu pacha, espacio donde entraban en plena conexión con los ancestros. La búsqueda y caza de estos animales, tanto en la quebrada de Humahuaca como en las ecorregiones adyacentes, para ritualizarlos y así lograr que transitaran por el inframundo de forma conjunta con los antepasados, debió tener por intención, además, hacer valer su posición en el sistema de reciprocidad. Solo la renovación de las relaciones recíprocas podía equilibrar las fuerzas de la naturaleza. Una de las principales vías para sostener este equilibrio, al parecer, fue el desarrollo de actos rituales y performativos en el Pucará, en los que mediante súplicas, invocaciones y ofrendas se debió encontrar el favor de distintas entidades vinculadas a los fenómenos meteorológicos y su temporalidad. Las evidencias detectadas en la kancha indican que, por ejemplo, en este espacio se ejecutaron ritos vinculados con el culto al sol, la fertilidad y los ancestros. La manifestación de ideas relacionadas con potenciar la producción posiblemente cobró mayor énfasis durante el esplendor de la ocupación incaica, por la necesidad de desarrollar un entorno sustentable para una densa población y un sistema económico expansivo. En este escenario, los ritos desplegados en el Pucará debieron estar conectados con las actividades de adoración a las 
wak'as locales, los cerros sagrados de Sixilera y Las Ánimas (Ochoa y Otero, 2020), entendidos como seres tutelares y proveedores de toda vida.

El registro material, por su parte, nos permite estimar que existió un conjunto de signos y significantes compartidos en distintas esferas que fue comprendido y connotado colectivamente. En el plano cosmológico e inmaterial, los comportamientos de los animales también debieron entenderse como zooindicadores o marcadores de tiempo al ser proyectados simbólicamente en el calendario ritual y productivo. Estos símbolos, de larga trayectoria en el tiempo, posiblemente sufrieron transformaciones en su modo de representación. No obstante, las creencias que los dioses andinos solo actuaban desde la reciprocidad y que la ofrenda de animales a los ancestros estaba vinculada a la prosperidad, parecen haber persistido hasta bien instalada la Colonia española. Esta larga biografía de entidades que se suceden, con distinto origen, no se rompió con el tiempo, al igual que la muerte no quebraba los vínculos entre los difuntos y su comunidad (Bouysse-Cassagne y Harris, 1987). Tampoco lo hizo el cambio de estado de los cuerpos en descomposición o el desmembramiento de las partes esqueletales. Las prácticas detectadas en el Pucará manifiestan que las ofrendas a los antepasados, ya fueran míticos o reales, humanos o animales, para pedir auxilio ante las fuerzas de la naturaleza siguieron vigentes por siglos; incluso debieron sumar nuevas rogativas.

La caída del Imperio incaico pudo llevar a un retroceso de la prevalencia del culto al sol como consecuencia de un refortalecimiento de las identidades locales y la búsqueda de una protección directa entre los ancestros (Ramírez, 2008). Este pudo ser el caso de la mujer hallada en la cima del Pucará. Su veneración en el tiempo posiblemente contempló la necesidad de contar con el respaldo de los ancestros ante la conquista europea. Su ajuar mortuorio demuestra la permanencia de prácticas rituales en las que se priorizaba la colocación de ofrendas compuestas por partes de animales y objetos con representaciones zoomorfas. El hallazgo del esqueleto de la vaca también puede ser percibido como parte de las manifestaciones de resistencia ante el culto católico. A diferencia del Dios cristiano, que concedía favores, los ancestros y las divinidades andinas solo respondían a cambio de la entrega de ofrendas. De allí que se sostuviera en el tiempo la reciprocidad a efectos de propiciar la fecundidad y evitar la ira de las entidades sobrenaturales, manifestada mediante alteraciones climáticas, pestes y hambrunas (Celestino, 1997).

En síntesis, las distintas representaciones detectadas en los objetos del Pucará permiten estimar que estos portaron sentidos y significados activos, necesarios para la promoción de las bases religiosas incaicas en las que posiblemente se recombinaron elementos propios de las creencias locales con la religión estatal. Con mayor o menor peso, según el período histórico de ocupación del Pucará, las prácticas rituales debieron cumplir con lo pautado por el culto al sol, los ancestros y la fertilidad. Las illas tanto las zoomorfas como las que representaban maíces, planta sumamente vinculada al sol, las "trompetas", los pucos con decoraciones serpentiformes, la vasija anuromorfa, los discos de metal, los keros y tantos otros elementos alegóricos de fertilidad al parecer se conjugaron en un mismo plano propiciatorio de fecundidad. A esta parafernalia se sumó la presencia del cuerpo o parte de los animales, antropomorfizados en múltiples direcciones para entrecruzar con cada acción lo terrenal con lo sobrenatural. Solo con el trabajo interdisciplinario, riguroso en cuanto a la revisión de la documentación histórica, el análisis de los contextos arqueológicos en correlato con la información antropológica y el estudio etnobiológico de los restos de fauna, se puede revitalizar estas articulaciones y en definitiva los rasgos materiales e inmateriales de la actividad humana y de la acción simbólica de los animales. 


\section{Agradecimientos}

A Gabriela Ammirati, Alejandra Reynoso, Victoria Coll, Silvia Manuale, Armando Mendoza, Daniel Aramayo, Presentación Aramayo, Guillermina Couso y Gabriel Alarcón, personal de los Depósitos de Arqueología de los museos Etnográfico "J.B. Ambrosetti”, Arqueológico "Dr. E. Casanova" y de Ciencias Naturales de la Universidad de La Plata, por su valiosa colaboración durante la revisión de las colecciones del Pucará de Tilcara. A Juan Repucci, Mario Ruiz Monachesi, Arturo Muñoz, Nicolás Pelegrin y Eduardo Etchepare por facilitarnos fotografías de diferentes especies de animales. A Alejandro Tablado, curador de la Colección de Invertebrados del Museo Argentino de Ciencias Naturales "Bernardino Rivadavia”, y a Beatriz Ventura, por ponernos en conocimiento de la existencia de la colección malacológica conservada en dicho museo. Esta investigación se sostuvo gracias al financiamiento de los subsidios otorgados por la Agencia Nacional de Promoción Científica y Tecnológica PICT 2015-2164 y por el Programa de Apoyo a la Investigación en el Instituto Interdisciplinario Tilcara (PAITI-FFyLUBA), $\mathrm{N}^{\circ} 2271$.

\section{Referencias citadas}

Akmentins, M.S. y C. Otero. (2016). Aproximaciones al significado de una pieza cerámica anuromorfa recuperada en un edificio ceremonial incaico del Pucará de Tilcara, Jujuy, Argentina. En Libro de resúmenes del I Congreso Argentino-Paraguayo de Herpetología, XII Congreso Argentino de Herpetología, II Congreso Paraguayo de Herpetología (pp. 69). Posadas: Asociación Herpetológica Argentina, Asociación Paraguaya de Herpetología.

Albornoz, Cristóbal de (1984 [1580]). Instrucción para descubrir todas las guacas del Pirú y sus camayos y haziendas. Edición de Pierre Duviols. Revista Andina, 1, 192-222.

Aliaga, C. I. (2006). Lo divino en la concepción andina. En Esterman, J. (Coord). Teología Andina. El tejido diverso de la fe indígena. Tomo II (pp. 51-80). La Paz: Plural Editores.

Allen, C. (2015). The whole world is watching: New perspectives on Andean animism. En Bray, T. (Ed.). The archaeology of Wak'as: Explorations of the sacred in the Pre-Columbian Andes (pp. 23-46). Boulder: University Press of Colorado.

Ambrosetti, J. B. (1902). El sepulcro de La Paya últimamente descubierto en los Valles Calchaquíes, Provincia de Salta. Anales del Museo Nacional, 8, 119-148.

Arriaga, I. A. (1621). Extirpación de Idolatría de Piru. Lima: Gerónimo de Contreras Impresor de Libros.

Barrionuevo, J. S. (2017). Frogs at the summits: phylogeny of the Andean frogs of the genus Telmatobius (Anura, Telmatobiidae) based on phenotypic characters. Cladistics, 33(1), 41-68.

Bauer, B. S. (2000). El espacio sagrado de los Incas. El sistema de ceques del Cuzco. Archivos de Historia Andina, 33. Cuzco: Centro Bartolomé de las Casas.

Bertonio, L. (1603a). Arte y grammatica muy copiosa de la lengua Aymara. Reeditado en 1879 por Julio Platzmann, Leipzig: Teubner. Roma: Zannetti.

Bertonio, L. (1603b). Arte breve de la lengua Aymara para introducción del arte grande de la misma lengua. Originalmente encuadernado al principio de 1603a. Roma: Zannetti. 
Bouysee-Cassagne, T. (1988). Lluvias y cenizas. Dos Pachacuti en la Historia. La Paz: Hisbol.

Bouysee-Cassagne, T. (2008). Minas del sol, del Inka y de la gente. Potosí en el contexto de la minería prehispánica. En Cruz, P. y Vacher, J. (Eds). Mina y metalurgia en los Andes del Sur desde la época prehispánica hasta el siglo XVII (pp. 303-348). Lima: Instituto Francés de Estudios Andinos.

Bouysse-Cassagne, T. y Harris, O. (1987). Pacha: en torno al pensamiento aymara. En Bouysse-Cassagne, T., Harris, O., Platt, T. y Cereceda, V. (Eds.). Tres reflexiones sobre el pensamiento andino (pp. 11-59). La Paz: Hisbol.

Bray, T. L. (Ed.). (2015). The archaeology of wak'as: explorations of the sacred in the pre-Columbian Andes. Colorado, CO: University Press of Colorado.

Bregante, O. (1926). Ensayo de clasificación de la cerámica del Noroeste Argentino. Buenos Aires: Editorial Estrada.

Calderari, M. (1991). Estilos cerámicos incaicos de La Paya. En Actas del XI Congreso Nacional de Arqueologia Chilena. Tomo II (pp. 151-163). Santiago.

Casanova, E. (1970). El Pucará de Tilcara (antecedentes, reconstrucción, guía). Publicación no 1 . Museo del Pucará de Tilcara. Buenos Aires: FFyL, Universidad de Buenos Aires.

Celestino, O. (1997). Transformaciones religiosas en los Andes peruanos. 1. Ciclos míticos y rituales. Gazeta de Antropología, 13, artículo 06. Recuperado de http://hdl.handle.net/10481/13567

Cereceda, V. (1987). Aproximaciones a una estética andina: de la belleza al Tinku. En Bouysee-Cassagne, T., Harris, O., Platt, T. y Cereceda, V. (Eds.). Tres reflexiones sobre el pensamiento andino (pp. 133-231). La Paz: Hisbol.

Cobo, B. (1964 [1653]). Historia del Nuevo Mundo. Biblioteca de Autores Espańoles. Tomos 91 y 92. Madrid: Ediciones Atlas.

Cornejo, M. (1998). La Guaca: un concepto de santuario en el Mundo Andino. En Actas del IV Congreso Internacional de Etnohistoria. Tomo III (pp. 60-72). Pontificia Universidad Católica del Perú. Lima: Fondo Editorial.

Debenedetti, S. (1930). Las Ruinas del Pucará de Tilcara, Tilcara, Quebrada de Humahuaca (Pcia. De Jujuy). Archivos del Museo Etnográfico II, Primera Parte. FFyL, Universidad de Buenos Aires.

Elías, R., Ramos, E., García, J., Herbert, M. y Quispe, J. (2019). Calling the Rains With the Help of the Lake Titicaca Frog. FrogLog 121, 27(1), 22.

García Escudero, M. C. (2009). El mundo de los muertos en la cosmovisión centroandina. Gazeta de Antropología, 25(2), artículo 51. Recuperado de http://hdl.handle.net/10481/6893.

Fink, R. (2001). La cosmología del dibujo del Altar del Quri Kancha según don Joan de Santa Cruz Pachacuti Yamqui Salca Maygua. Histórica, 25(1), 9-75.

Frost D. R. (2020). Amphibian Species of the World: an Online Reference. Version 6.1. Disponible en http://research.amnh.org/herpetology/amphibia/index.html.

Garcilaso de la Vega, I. (1944 [1609]). Obras completas del Inca Garcilaso de la Vega (edición y estudio preliminar de C. Sánez de Santa María, S.J.). Madrid: Biblioteca de Autores Españoles CXXXII-CXXXV, Atlas. 
Gisbert, T. (1980). Iconografía y Mitos Indigenas en el Arte. La Paz: Gisbert.

Gisbert, T. (2001). El paraiso de los pájaros parlantes. La imagen del otro en la cultura andina. La Paz: Plural Editores.

Golte, J. (2015). Moche: Cosmología y Sociedad. Una interpretación iconográfica. Perú: Instituto de Estudios Peruanos - IEP, Centro Bartolomé de las Casas.

González, A. R. (1992). Las placas metálicas de los Andes del sur. Mainz am Rhein: Verlag Philipp von Zabern.

Guaman Poma de Ayala, F. (2006 [1615]). Nueva coronica y buen gobierno. México: Ed. Siglo XXI.

Gudemos, M. L. (1998). Antiguos Sonidos. El material arqueológico musical del Museo Dr. Eduardo Casanova. Tilcara, Jujuy (Rep. Argentina). Tilcara: Instituto Interdisciplinario Tilcara, FFyL-UBA.

Gudemos, M. L. (2009). Trompetas andinas prehispánicas. Tradiciones constructivas y relaciones de poder. Anales del Museo de América, 17: 184-224.

Gutiérrez Usillos, A. (2002). Dioses, simbolos y alimentación en los Andes. Ecuador: Ediciones Abya-Yala.

Harris, O. y Bouysse-Cassagne, T. (1988). Pacha: en torno al pensamiento aymara. En Albo, X. (Comp.). Raices de América: el mundo aymara (pp. 217-274). Madrid: Alianza Editorial - Unesco.

Hyslop, J. (1990). Inka Settlement Planning. Austin, TX: University of Texas Press.

Kosiba, S. y Bauer, A. (2014). Mapeando el paisaje político: hacia un análisis SIG de las diferencias medioambientales y sociales. Cuadernos de Qhapaq Nan, 2, 120-160.

Kosiba, S. (2016). Review of Izumi Shimada. The Inka Empire: A Multidisciplinary Approach. University of Texas Press, Austin, TX. Antiquity, 90(349), 267-269.

Krapovickas, P. (1958/1959). Un Taller Lapidario en el Pucará de Tilcara. RUNA, 9, 139-151.

Lafón, C. R. (1956/1957). Sobre algunos artefactos de hueso de la Quebrada de Humahuaca. RUNA, 3(2), $203-231$.

Lavilla E. O. y Barrionuevo, J. S. (2005). El género Telmatobius (Anura: Leptodactylidae) en la República Argentina: una síntesis. En Lavilla, E. O. y De la Riva, I. (Eds.). Estudios Sobre las Ranas Andinas de los Géneros Telmatobius y Batrachophrynus (Anura: Leptdactylidae). Monografías de Herpetología 7 (pp. 115165). Valencia, España: Asociación Herpetológica Española.

Lopez Geronazzo, L. N., Otero, C., Álvarez, A., Ercoli, M. D. y Cortés-Delgado, N. (2019). Identification of guinea pig remains in the Pucará de Tilcara (Jujuy, Argentina): Evidence in favor of the presence of the Andean breed in the Quebrada de Humahuaca. International Journal of Osteoarchaeology, 29: 934-946.

Lopez Geronazzo, L. N., Musaubach, M. G. y Otero, C. (2019). Explorando protocolos interdisciplinarios para el estudio de plantas y animales en ajuares funerarios prehispánicos de la Quebrada de Humahuaca (Jujuy, Argentina). En Libro de resúmenes de las XIII Jornadas Regionales de Investigación en Humanidades y Ciencias Sociales. Facultad de Humanidades y Ciencias Sociales. San Salvador de Jujuy: EDIUNJu.

Madrazo, G. B. y Otonello, M. (1966). Tipos de Instalación Prehispánica en la Región de la Puna y su Borde. Monografías N 1. Olavarría: Museo Etnográfico Municipal "Dámaso Arce”. 
Malpass, M. A. y Alconini, S. (2010). Provincial Inka Studies in the Twenty-first Century. En Malpass, M. y Alconini, S. (Eds.). Distant Provinces of the Inka Empire. Toward a deeper understanding of Inka Imperialism (pp. 1-13). Iowa City, IA: University of Iowa Press.

Manríquez, V. (1999). El término Ylla y su potencial simbólico en el Tawantinsuyu. Una reflexión acerca de la presencia Inca en Caspana (río Loa, Desierto de Atacama). Estudios Atacameños, 18, 107-118.

Marengo, C. (1954). El Antigal de Los Amarillos. Buenos Aires: Publicaciones del Instituto de Arqueología $\mathrm{N}^{\circ}$ II.

Martínez Cereceda, J. L. (1995). Autoridades en los Andes, los atributos del Señor. Lima, Perú: Fondo Editorial de la Pontificia Universidad Católica del Perú.

Méndez, M., Sánchez, C., Otero, C. y Lupo, L. (2019). Análisis arqueopalinológico de un contexto mortuorio en el Pucará de Tilcara (Quebrada de Humahuaca, Jujuy). En Revista de Resúmenes de las XXXVII Jornadas Argentinas de Botánica, (pp. 284-285). Córdoba: Boletín de la Sociedad Argentina de Botánica.

Menzel, D. (1976). Pottery Style and Society in Ancient Peru. Art as a Mirror of History in the lca Valley, 13501570. Berkeley, CA: University of California Press.

Montes, F. (1999). La Máscara de Piedra. Simbolismo y personalidad aymaras en la historia. La Paz: Armonía.

Murra, J. V. (2002). El mundo Andino, población, medio ambiente y economía. Lima: Pontificia Universidad Católica del Perú. Instituto de Estudios Peruanos.

Murúa, Martín de (1943 [1573]). Fábulas y ritos de los Incas, Lima.

Nielsen, A. E. (2007a). Bajo el hechizo de los emblemas: Políticas corporativas y tráfico interregional en los Andes Circumpuneños. En Nielsen, A., Rivolta, M. C., Seldes, V., Vázquez. M. y Mercolli, P. (Comps). Producción y Circulación Prehispánicas de Bienes en el Sur Andino (pp. 393-411). Córdoba: Editorial Brujas.

Nielsen, A. E. (2007b). Armas significantes: tramas culturales, guerra y cambio social en el sur andino prehispánico. Boletín del Museo Chileno de Arte Precolombino, 12(1), 9-41.

Nielsen, A. E. (1998). Impacto y organización del dominio Inka en Humahuaca. Tawantinsuyu 4, Canberra.

Nordenskiöld, E. (1930). Huayru Game. Journal de la Société des Américanistes. Tome 22, 211-213.

Núñez Atencio, L. y Castro, V. (2011). ¡Caiatunar, caiatunar! Pervivencia de ritos de fertilidad prehispánica en la clandestinidad del NOA (norte de Chile). Estudios Atacameños. Arqueología y Antropologías Surandinas, 42, 153-172.

Núñez Rebaza, L. (1992). La piedra de Huamanga. En Artesanía peruana. Orígenes y evolución (pp. 173-183). Lima: Editorial Allpa.

Ochoa, P. A. y Otero, C. (2020). Usos productivos y rituales de las rutas incaicas del sector central de la Quebrada de Humahuaca (Jujuy, Argentina). Chungara, Revista de Antropología Chilena, 52(3), 427-444.

Oros Rodríguez, V. (2015). Retablos y Piedras Santos. La materialidad de las Wak'as. Museo Nacional de Etnografía y Folklore. La Paz: Fondo Cultural del Banco Central de Bolivia.

Otero, C. (2015). Distribución y consumo de cerámica inca en el Pucará de Tilcara (Quebrada de Humahuaca, Argentina). Chungara. Revista de Antropología Chilena, 47, 401-414. 
Otero, C. (2017). Ceramics styles from Pucara de Tilcara settlement during inca domination. En Scaro, A., Otero, C. y Cremonte, M. B. (Eds.). Pre-inca and inca pottery. Quebrada de Humahuaca, Argentina (pp. 107-138). Cham, Suiza: The Latin American Studies Book Series, Springer.

Otero, C., Akmentins, M. S. e Ibarra, C. M. (2018b). Expresiones de creencias. Representaciones de animales en soportes de hueso, metal y cerámica del Pucará de Tilcara (Quebrada de Humahuaca, Argentina). En Libro de resúmenes del "XXI Congreso Nacional de Arqueología Chilena (pp. 27-31). Santiago de Chile: Sociedad Chilena de Arqueología - Universidad Alberto Hurtado.

Otero, C., Bordach, M. A. y Mendonça, O. J. (2017). Las prácticas funerarias en el Pucará de Tilcara (Jujuy, Argentina). Nuevos aportes para su conocimiento desde la Unidad Habitacional 1. Antípodas. Revista de Antropología y Arqueología, 27, 141-163.

Otero, C., Centeno, N., Fuchs, M. L., Gheggi, M. S. y Seldes, V. (2019). Aportes desde la Entomología Forense y la Bioantropología al análisis del comportamiento mortuorio en el Pucara de Tilcara (Quebrada de Humahuaca, Jujuy). En Libro de Resúmenes XX Congreso Nacional de Arqueología Argentina: 50 años de arqueologías. Córdoba, Argentina: DACOR.

Otero, C., Cremonte, M. B. y Ochoa, P. A. (2018). La construcción del poder incaico en la Quebrada de Humahuaca (Jujuy, Argentina). En Muñoz, M. A. (Ed.). Interpretando Huellas: Arqueología, Etnohistoria y Etnografía de los Andes y sus Tierras Bajas (pp. 227-245). Cochabamba: Grupo Editorial Kipus.

Otero, C. y Ochoa, P. A. (2011). Primeras aproximaciones a la materialización del tiempo y las prácticas productivas especializadas en Tilcara (Quebrada de Humahuaca, Jujuy). Revista Estudios Sociales del NOA. Nueva Serie, 11, 101-122.

Otero, C. y Tarragó, M. N. (2017). Reconstructing Inca socioeconomic organization through biography analyses of residential houses and workshops of Pucara de Tilcara (Quebrada de Humahuaca, Argentine). Journal of Anthropology and Archaeology, 5(1), 55-72.

Pardo, L. (1939). Clasificación de la cerámica cuzqueña. Revista del Museo e Instituto Arqueológico, 4(6-7), 3-27.

Pérez, A. E., Schuster, V. y Jofré P., D. (2018). Amphibiomorphic Modeled and Painted Pottery from Argentine Patagonia and Central-Southern Chile. Functional Interpretation and Identification of Species Based on Mimetic and Aposematic Traits. Open Archaeology 2018, 4, 394-405.

Pérez Gollán, J. A. y Gordillo E. I. (1993). Alucinógenos y sociedades indígenas del Noroeste argentino. Anales de Antropologia, 30(1), 299-350.

Polo de Ondegardo, J. (1916 [1571]). Informaciones acerca de la religión y Gobierno de los Incas. Lima: Imprenta y Librería San Martín y Cía.

Ramírez, S. E. (2005). To feed and be fed. The cosmological bases of authority and identity in the Andes. California, CA: Stanford University Press.

Ramírez, S. E. (2008). Negociando el imperio: el estado inca como culto. Bulletin de l'Institut Français d'Études Andines, 37(1), 5-18.

Ramos Gavilán, F. A. (1976 [1621]). Historia de Nuestra Señora de Copacabana. La Paz: Academia Boliviana de la Historia. 
Rostworowski de Diez Canseco, M. (1999). Historia del Tahuantinsuyu. Lima: Instituto de Estudios Peruanos.

Rowe, J. H. (2003). Los Incas del Cuzco. Siglos XVI-XVII-XVIII. Cusco: Instituto Nacional de Cultura, Región Cusco, Multi e Imprenta Edmundo Pantigoso EIRL.

Salas, A. M. (1945). El Antigal de Ciénaga Grande (Quebrada de Purmamarca, Pcia. de Jujuy). Buenos Aires: Publicación del Museo Etnográfico (FFyL-UBA). Serie A, V.

Sánchez, S. (1996). Fragmentos de un tiempo largo. Tilcara entre fines del siglo XVI y principios del XIX. Tesis de Licenciatura inédita. Facultad de Humanidades y Ciencias Sociales, Universidad Nacional de Jujuy. Jujuy. Ms.

Sánchez, S. y Sica, G. (1998). Entre águilas y halcones. Relaciones y representantes del poder en los Andes Centro-Sur. En Actas del IV Congreso Internacional de Etnohistoria. Tomo I (pp 169-202). Lima: Pontificia Universidad Católica del Perú. Fondo Editorial.

Sánchez Canedo, W., Bustamante Rocha, M. y Villanueva Criales, J. (2016). La Chuwa del Cielo. Los animales celestiales y el ciclo anual altiplánico desde la biografia social de un objeto. La Paz: MUSEF.

Sandoval Chayña, P. (2009). Señas Ancestrales como Indicadores Biológicos de Alerta Temprana. Programa Mundial de Alimentos, Perú.

Sanhueza, C. (2005). Espacio y tiempo en los límites del Mundo. Los Incas en el despoblado de Atacama. Boletín del Museo Chileno de Arte Precolombino, 10(2), 51-77.

Shimada, I. (2018). El Imperio Inca. Lima: Fondo Editorial de la Pontificia Universidad Católica del Perú.

San Román, F. ([1890] 1966). La Lengua cunza de los naturales de Atacama. Ancora, 3, 76-88. Antofagasta: Universidad de Chile.

Stastny, F. (1981). Las Artes Populares del Perú. Lima: Ediciones Edubanco.

Steele, P. R. y Allen, C. J. (2004). Handbook of Inca mythology. California, CA: ABC-CLIO.

Tarragó, M. N.; González, L. R., Ávalos, G. y Lamamí, M. (2010). Oro de los Señores. La tumba 11 de La Isla de Tilcara (Jujuy, Noroeste Argentino). Boletín del Museo Chileno de Arte Precolombino, 15(2), 47-63.

Urton, G. (2005). En el cruce de la Tierra y el Cielo. Cusco: Centro de Estudios Regionales Andinos Bartolomé de Las Casas.

Van Kessel, J. (2006). Economía bidimensional: dos paradigmas de (meta)-economía comparados: el andino-tradicional y el cristiano-medieval. En Esterman, J. (Coord.). Teología Andina. El tejido diverso de la fe indigena. Tomo II (pp. 221-248). La Paz: Plural Editores.

Vilte Vilte, J. (2004). Diccionario Kunza-Español/ Español-Kunza. Lengua del Pueblo Lickan o Atacameño. Santiago de Chile: Codelco Chile.

Williams, J. D., (1988). Las Corales. En Anfibios y reptiles. Fauna Argentina 2 (pp. 1-32). Buenos Aires: Centro Editor de América Latina.

Zaburlín, M. A. y Otero, C. (2014). Un manuscrito olvidado de J.B. Ambrosetti: "Exploraciones arqueológicas en la antigua ciudad del Pukará de Tilcara. En Aparicio et al. (Eds.). Colección Saberes. Investigaciones 
del Instituto Interdisciplinario Tilcara (pp. 161-220). Buenos Aires: Editorial de la FFyL, Universidad de Buenos Aires.

Zuidema, T. (1977). The Inca Calendar. En Aveni, A. (Ed.). Native American Astronomy (pp. 219-259). Austin, TX: University of Texas Press.

Zuidema, T. (1985). The Lion in the City: Royal Symbols of Transition in Cuzco. En Urton, G. (Ed.). Animal Myths and Metaphors, (pp. 183-250). Salt Lake City, UT: University of Utah Press.

Zuidema, T. (2015). El calendario inca: tiempo y espacio en la organización ritual del Cuzco. La idea del pasado. Lima: Fondo Editorial del Congreso del Perú y Fondo Editorial de la Pontificia Universidad Católica del Perú. 